\title{
Los aranceles de la ciudad de Granada al final de la Edad Media
}

\author{
Carmen Trillo San José*
}

\section{INTRODUCCIÓN}

Uno de los temas menos tratados hasta el presente en el panorama historiográfico granadino es, sin duda, el del comercio. De hecho, de los pocos estudios que se han realizado hasta el momento las actividades comerciales con el exterior han sido las que más han llamado la atención. A este respecto, los trabajos de López de Coca, lo ponen de manifiesto (LOPEZ DE COCA 1978, 1982).

Es evidente que se puede acceder de manera más asequible a ese tráfico comercial, del que queda una constancia mayor. Al mismo tiempo, se ha de considerar que los intercambios que giran en torno a pequeños núcleos de población, no tienen la misma entidad que los que se pueden documentar en las grandes ciudades. Así, cuando los castellanos intentan controlar y, a la vez, modificar el tráfico comercial de Granada, capital del reino y el máximo exponente de la organización urbana nazarí, lo hacen precisando el flujo de mercancías que llegan habitualmente a ella y también la organización viaria para su conducción y entrada en la ciudad. Los distintos productos debían acceder por unas puertas previamente señaladas. Estas eran, fundamentalmente, las de Elvira, Birrambla y Guadix. Distantes las unas de las otras abrían la ciudad por extremos diferentes y permitían que las mercancías llegaran hasta el corazón de la misma. La de Elvira, del siglo $\mathrm{XI}$, aunque reconstruida en época nazarí y posteriormente, era el punto de contacto con la parte occidental de la Vega. La de Birrambla, probablemente también de la misma época, permitía la comunicación con el sur, y era la más próxima al centro de la madīna. Por último, la de Guadix, Ilamada Bāb alŠumays, o puerta del Solecito, situada entre la Cuesta del Chapiz y el Paseo de los Tristes, facilitaba la entrada en el Albaicín.

Una vez atravesada la puerta, según las disposiciones reales, mercaderes y mercancías debían dirigirse directamente, sin descargar en ninguna parte, a la alhóndiga o tiendas en donde se vendían. Allí los recaudadores recibían el alcabala de todo lo que estaba destinado a la venta. El fraude en el itinerario se llamaba descaminado y se saldaba con el pago del doble del valor de la alcabala (TRILLO 1993).

Otro de los aspectos que se pueden determinar es el de las mercancías que llegaban a la ciudad gracias a aranceles como el que hoy publicamos,' y que se dieron para otros lugares andaluces, dentro de un plan general de control del comercio emprendido por los Reyes Católicos (GONZÁLEZ 1981: p. 145). Sin embargo, los aranceles no suministran una información suficiente como para conocer la naturaleza de este tráfico comercial y sus fluctuaciones.

El reino nazarí era de una gran importancia como enclave que permitía el tráfico con Berbería y el suministro a Europa occidental de

* Universidad de Granada.

I A.G.S., R.G.S., |||-|50|, sin foliar 
productos que en otro tiempo venían de Oriente. La agricultura especulativa que se practicaba en él proporcionaba artículos exóticos para el resto del continente, como la seda, el azúcar, las pasas, etc., que sustituían productos orientales más caros. El regadío, en efecto, había permitido la adaptación al clima mediterráneo de especies vegetales tropicales y subtropicales traídas por los árabes a la Península, como la caña de azúcar. Este comercio era dirigido por italianos, sobre todo, genoveses, aunque también florentinos y lombardos, desde los puertos de Almería, y, sobre todo desde el final del siglo XIV, de Málaga y Almuñécar.

Junto a esta economía mercantil y urbana había otra de autoabastecimiento que se basaba en una agricultura de policultivo y regadío y una ganadería poco desarrollada, cuyos productos también se vendían en Granada: fruta verde y seca, aceitunas, uvas, miel, cera, aceite, queso, sebo, pescado fresco y salado (TRILLO 1993: pp. 38 y 39).

No obstante, los aranceles que editamos se refieren en su mayoría a artículos de lujo o, al menos, no de un intercambio ordinario, buena parte de los cuales no se producen en Granada. Resinas, perfumes, tintes y especias, son los más mencionados. Al lado de ellos, es cierto, hay otros que provienen de nuestra región o que son de uso corriente: pasas, seda, higos, cochinilla, almáciga, sal, jabón, miel, queso, manteca, etc.

\section{EL DOCUMENTO}

El documento que editamos se encuentra en el Archivo General de Simancas, Registro General del Sello, III- I50I, sin foliar. Se trata de los aranceles de las mercancías que entraban en la ciudad de Granada en I50 I. Están hechos a imagen de los de la ciudad de Sevilla. La única información que suministran es, además, del nombre del producto, el precio por arroba. En ellos se recogen un total de 137 artículos de los que rara vez se especifica su origen, aunque cabe pensar que procedían de lugares diversos. Así, en las pocas ocasiones en que se explicita podemos ver que algunos vienen de lugares lejanos, de Oriente, como la nuez moscada de Xarque, o el lino de Alejandría, mientras que otros son de la propia región granadina, como los higos de la tierra, por ejemplo.

La clasificación realizada en el cuadro que sigue es meramente indicativa y sólo pretende facilitar la comprensión del conjunto de los artículos que entraban a Granada. Algunos de ellos podían pertenecer a más de un grupo. Del total de mercancías documentadas el 23,35\% corresponde a perfumes, resinas y drogas medicinales de origen vegetal, ya elaborados o destinados a la composición de otros productos. El 19,17\% de los artículos mencionados son minerales y metales. El 15,32\% son productos alimenticios: frutos, azúcar, e incluso, dulces como el alajú o el alfeñique. El 10,21\% reune especias y condimentos. El 9,48\% se refiere a tintes y taninos utilizados en la curtiduría y en la industria textil. El 4,37\% comprende varios tipos de tejidos o de fibras para tejer: seda de varias clases, algodón, lana y lino. El $4,37 \%$ son productos manufacturados como espejos, pailones, bacines, jabón, etc. El 4,36\% son materias de origen animal y se usaban para elaborar otros artículos: ballena (que puede ser aceite o cualquier parte de la misma), coral, cera, cerdas, plumas, y castor, del que se obtenía un perfume. Un 8,75\% corresponde a artículos de cuyo significado no estamos seguros.

Existe una copia de estos aranceles en las Ordenanzas de Granada de 1667. En el glosario que sigue a continuación se han actualizado los nombres correspondientes, siempre que ha sido posible. El nombre en cursiva seguido de la palabra entre corchetes doc., se refiere al término encontrado en el documento que añadimos en el apéndice documental, el que ha servido de base a nuestro trabajo, es decir, A.G.S., R.G.S., III-I50I. Si existen diferencias respecto a la copia de las Ordenanzas de Granada, ponemos también esta variante en cursiva, seguida del nombre entre corchetes Ord.. Las referencias a fuentes documentales inéditas como, por ejemplo, la obra del Padre Guadix, autor de un diccionario etimológico de palabras castellanas de origen árabe, escrito a finales del XVI, que se conserva en la Biblioteca Colombina de Sevilla, aparecen también entre corchetes. 


\begin{tabular}{|c|c|c|c|c|c|c|c|c|}
\hline ALIMENTOS & $\begin{array}{c}\text { ESPECIAS } \\
\text { CONDIMENTOS }\end{array}$ & $\begin{array}{l}\text { PERFUMES Y } \\
\text { DROGAS }\end{array}$ & $\begin{array}{l}\text { TINTES Y } \\
\text { TANINOS }\end{array}$ & TELAS & MINERALES & $\begin{array}{c}\text { PROD. DE } \\
\text { ORIG. ANIMAL }\end{array}$ & $\begin{array}{l}\text { PRODUCTOS } \\
\text { ELABORADOS }\end{array}$ & DUDOSOS \\
\hline alajú & alazor & ajonje & agalla & algodón & acero & ballena & bacín & abeytun \\
\hline alfeñique & alcaravea & alcanfor & alheña & cadarzo & acije & cera & bocín & alnoxacar \\
\hline alfóstigo & azafrán & alhucema & añil & lana & albayalde & cerdas & espejo & $\begin{array}{l}\text { azúcar } \\
\text { rosado }\end{array}$ \\
\hline almendra & canela & almáciga & bermellón & lino & alcohol & coral & jabón & camarmedes \\
\hline arroz & clavo de girofre & almea & brasil & seda & almagra & plumas & pailón & çentual \\
\hline avenate & comino & almoradux & cardenillo & & alumbre & testículos befre & pez & jauli \\
\hline azúcar & fustes & alquitira & casca & & atutía & & & loreguilla \\
\hline bellota & jengibre & amapola & grana & & azarcón & & & maçacote \\
\hline congrio & macia & ambar & oropimente & & azofar & & & pedrelongo \\
\hline dátil & matalahuga & anime & pastel & & azogue & & & rocoche \\
\hline grasa & nuez moscada & bayón & rubia & & azufre & & & xemis \\
\hline higo & pimienta & buto & urchilla & & cobre & & & $\begin{array}{c}\text { yerva de } \\
\text { vastro }\end{array}$ \\
\hline manteca & sal de compás & cañafístola & zumaque & & esmalte & & & \\
\hline miel & & espique & & & estaño & & & \\
\hline pasa & & estoraque & & & greda & & & \\
\hline queso & & galang & & & ahierro & & & \\
\hline \multirow[t]{14}{*}{ sebo } & & galbano & & & hojalata & & & \\
\hline & & gallón & & & latón & & & \\
\hline & & goma & & & plomo & & & \\
\hline & & henenta & & & pólvora & & & \\
\hline & & incienso & & & rejalgar & & & \\
\hline & & aceite de laurel & & & salitre & & & \\
\hline & & mirobálanos & & & solimán & & & \\
\hline & & resina & & & vidrio & & & \\
\hline & & ruibarbo & & & yeso & & & \\
\hline & & sándalo & & & & & & \\
\hline & & sen & & & & & & \\
\hline & & triaca & & & & & & \\
\hline & & turbit & & & & & & \\
\hline & & violeta & & & & & & \\
\hline
\end{tabular}

\section{GLOSARIO}

\section{Abeytun [doc.]. Albeytan[Ord.].- No identificada.}

Aceite de laurel. Açeyte de laurel [doc.]. Azeyte del candil [Ord.].- El laurel es árbol del familia de las lauráceas, cuyas hojas son usadas como condimento (D.R.A.E.). El fruto y la semilla del laurel contienen un $25 \%$ de aceite. Es una manteca calmante que se usaba como carminativo después de untarla en el vientre (FONT 1978: p.20I).

Acero. Azero [doc.].- Aleación de hierro y carbono. Se daba este nombre a diversos preparados de hierro, especialmente a las aguas ferruginosas que se empleaban contra la opilación, la anemia y estados de debilidad (D.R.A.E.).

Acije. Azije [doc.]. Azige [Ord.].- Aceche o aciche. Caparrosa (D.R.A.E). "Llaman en algunas partes de España a una droga que es uno de los materiales con que se haze tinta para escreuir" [P. Guadix].
Agalla. Agallas [doc.]. I. Excrecencia redonda que se forma en el roble, alcornoque y otros árboles y arbustos por la picadura de ciertos insectos al depositar sus huevos (D.R.A.E.). Se sabe que la agalla (Cynips gallae tinctoriae) es un insecto cuya picadura produce excrecencias en las ramas de la encina y de otros árboles de la misma familia. Estas excrecencias encierran gran cantidad de tanino y tienen propiedades astringentes que hacen de él un ingrediente útil en medicina y en ciertas industrias. Se la prefería pesada y de color verdoso. La de color amarillo se consideraba de mala calidad. Venía a Occi-dente generalmente de Grecia y de Asia Menor (HEYD 1967: II, p.643). "Llaman en España a una frutilla vana de roble y a otra de cipres" [P. Guadix].

Agallado.- Dícese de lo que está metido en tinta de agallas molidas, a fin de que tome pie para el color negro (D.R.A.E.).

Ajonge. Ajonge- Sustancia crasa que se saca de la raíz de la ajonjera y sirve, como la liga, para coger pájaros (D.R.A.E.) 
Alajú. Aleguz [doc.]. Alarguez [Ord.].- Pasta de almendras, nueces $y$, a veces, piñones, pan rallado y tostado, especia fina y miel bien cocida. Dulce hecho con esta pasta (D.R.A.E.). "Alajuz: Ilaman (en algunas partes de España) a çierta comidilla o golosinilla dulçe, vease el nombre alaxuz; alaxub: llaman en España a çierta suerte de nuegados o mercocha en que interuiene pimienta y cosas calientes (cosa bien propia) para estomagos frios 0 de viejos" [P. Guadix].

Alazor. Alançor [doc.]. Alanzor [Ord.].- (Del ár. al-casfur, el cártamo). Planta anual de la familia de las compuestas, flores de color azafrán que se usan para teñir, cuya semilla ovalada, blanca y lustrosa produce aceite comestible y sirve también para cebar aves (D.R.A.E.). "Llaman en España a una mata ortense cuya flor es de color y manera de hebras de açafran" [P. Guadix].

Albayalde. Alvayalde [doc.]. Albayalde [Ord.].(Del ár. al-bayāộ) Carbonato básico de plomo. Es sólido y blanco (D.R.A.E.). "Llaman en España a una droga medicinal que venden los especieros y usan della las mugeres porque presta y da blancura" [P. Guadix].

Alcaravea.-Alcaravea [doc.]. Alcarauea [Ord.].Planta de la familia de las umbelíferas y semillas pequeñas que por ser aromáticas sirven para condimento (D.R.A.E.). Es del tamaño del comino, menos redondo, y mas largo, aromático y picante (D.A.). "Llaman en España a çierta similla comestible que sirue a los cozineros por suerte de especie para los guisados" [P. Guadix].

Alcohol.- Alcohol [doc.]. Alcoxol [Ord.]. (Del ár. al-kuhl colirio). Polvo finísimo usado como afeite por las mujeres para ennegrecerse los bordes de los párpados, las pestañas, las cejas o el pelo. Hacíase con antimonio o con galena y después con negro de humo perfumado (D.R.A.E.). "Aquellas mugéres que pintan las caras, y alcoholan los ojos, y tiñen las bocas, escandalizan de mala manéra los ojos de los christianos" (D.A.). "Es cierto género de polvos que con un palito de hinojo teñido en ellos le passan por los ojos para aclarar la vista y poner negras las pestañas y para hermosearlos" (COVARRUBIAS 1984). "C'est la galène ou sulfure de plomb, ce qui a été reconnu d'ailleur sur un échantillon que j'ai apporté. C'est à tort que plusieurs auteurs ont traduit le mot alcohol par antimoine" (DOZY 1967: II, p. 446). En la Alpujarra se pagaba en 1496 un "derecho de la sierra del Alcohol" en las țā́as de Andarax y Berja (TRILLO 1994: p. 309).

Alfeñique. Alfeñique [doc.]. - Pasta de azúcar cocida y estirada en barras muy delgadas y retorcidas (D.R.A.E.). Pasta de azúcar que se suaviza con azéite de almendras dulces, que regularmente se toma en las fluxiónes catarrales para ablandar el pecho [D.A.]. "Al-fânīd, origen de nuestro arabismo "alfeñique", procede del persa pānīd, con el que se designaba tanto a una variedad de dulce como a la variedad de azúcar. Ibn al-Jațib menciona los alfeñiques como unos de los manjares que se comín en la celebración del mawlid (o fiesta del nacimiento del Profeta) en el palacio de la Alhambra durante el reinado de Muhāmmad V (1362): "en las mesas se arracimaba exquisito alfeñique, que deja chiquito al mejor țabarzad[persa], relleno de almendras, que abría el apetito con el incentivo de aromas indios y de digestivos medicinales" (GARCÍA SÁNCHEZ 1990: p. 220).

Alfóstigo.- Alfóncigo. Alfostigos [doc.]. Fruto del alfóncigo, árbol de la familia de las anarcardiáceas, de color verdoso, oleaginoso, dulce y comestible llamado pistacho (D.R.A.E.).

Algodón.- Algodon frisado e en pelo [doc.] Algodon hilado, e en pelo [Ord.]. Borra larga y blanca que nace de una planta de la familia de las malváceas, que se emplea para hacer tejidos (D.R.A.E.). El algodón, supuestamente originario de la India, fue descubierto por los árabes allí o en el Golfo Pérsico y el valle del Jordán y, más tarde, difundido por ellos. A principios de la era islámica se desarrolló una nueva variedad de algodón -el herbáceo o anual- lo que permitió su cultivo en climas de veranos cálidos e inviernos fríos (WATSON 199।: p. 8). Se producía algodón en varios lugares de Europa (Creta, España, Calabria, etc.) pero para encontrar algodón de buena calidad había que salir de los límites de la cristiandad (HEYD 1967: II, p.6II). "Llaman en España a çierta lanilla blanca que se coge de una yerua que se llama algodonera y la hilan las mugeres y hazen della telas para vestuarios" [P. Guadix]. El documento menciona "Del algodon frisado e en pelo, çinco maravedis" [doc.], es decir, levantado, rizado.

Alheña. Alheña [doc.].- Polvo al que se reducen las hojas de un arbusto de la familia de las oleáceas, cogidas en primavera y que sirve para teñir (D.R.A.E.). Arbusto cuyas hojas y raíces reducidas a polvo y disueltas en agua se empleaban para teñir y en cosmética femenina. Se usaba masivamente en industria textil como materia tintórea, en sustitución de otros tintes más caros y apreciados como la grana o la rubia. "Les habitants de l'andalousie ne portent pas de turbant, mais ils prennent le plus grand soin de leur chevelure, qu'ils nettoient et qu'ils teignent au henné, tant qu'elle n'est pas entièrement blanche" [AL-CUMARĪ 1927: pp. 236-235]. Se siembra en regadío en los meses de abril o mayo y al final de septiembre se arranca la hoja. Era un cultivo frecuente en la Alpujarra, sobre él recaía el "derecho de la alheña" en I496 
(TRILLO 1994: p. 222). "Llaman en España a çierta mata o arbusto que paresçe ser espeçie de çumaque" [P. Guadix].

Alhucema.- Alhuçema [doc.]. Algucema [Ord.]. Espliego. Planta de las labiadas, aromática, de cuyas flores se extrae un aceite esencial muy usado en perfumería. Semilla de esta planta que se utiliza como sahumerio (D.R.A.E.). "Llaman en algunas partes de España a una yerua silvestre odorifera y mediçinal a que (por mejor nombre) llaman espliego" [P. Guadix].

Almáciga. Almaçiga [doc.]. Almaciga [Ord.].Resina clara, translúcida, amarillenta y algo aromática que se extrae de una variedad de lentisco (D.R.A.E.). Dice Dioscórides que "produce también el lentisco resina, la qual vnos llaman lentiscina, y otros almastiga... y maxcada engendra muy buen olor en la boca, y aprieta las relaxadas enzias. Nace abundante y excellentissima en la isla de Chio. Tienese por mejor, la que reluze como luciernega, y en su blancura se parece à la cera Toscana, siendo gruessa, tostada, fragil, y de suaue olor. De la verde no se haze tanto caudal. Adulteranla con encienso, y con resina de piñas" (LAGUNA 1968: I, p. 55]. Pío Font Quer dice que aunque algunos piensan que sólo se obtiene de una variedad de lentisco, como la que se da en la isla de Quío (Pistacia lentiscus, variedad chia), también de los de la Península Ibérica (Pistacia lentiscus L.) se obtiene este producto (FONT QUER 1978: p. 440). El Botánico anónimo del siglo XII señala que "cilk es la resina que se masca, llamada en “aŷamiyya, machcaira" (ASIN 1944: p. 156). Almaciga goma, máztque (ALCALA 1917: p. 98]. "Llaman en algunas partes de España a çierta droga algo medicinal" [P. Guadix].

Almagra.- Almagra [doc.].- (Del ár. al-magra, la tierra roja). Almagre, óxido de hierro (D.R.A.E.). "Especie de tierra colorada mui semejante al Bol arménico, que sirve para teñir, ò untar diferentes cosas: como las lanas, las tablas y los cordéles de que usan los carpinteros para señalar las líneas en los madéros que quieren asserrar" (D.A.).

Almea.- Almea [doc.]. I. Azúmbar, bálsamo de estoraque. 2. Corteza del estoraque, después que se le ha sacado toda la resina (D.R.A.E.). "Llaman a çierta droga o goma medicinal" [P. Guadix].

Almendra. Almendra[doc.]- Fruto del almendro (D.R.A.E.). "L'amande y est de même abondante [en Málaga], belle et exquise" (AL-CUMARI 1927: p. 24I).

Almoradux. Almoradux [doc.]. Almoraduz [Ord.].- (Del ár. al-murdadūš, la mejorana). Mejorana. También sándalo (D.R.A.E.). "Llaman en
España a cierta mata silvestre (y en alguna manera) odorifera" [P. Guadix].

Alnoxacar [doc.]. Alnoxaca [Ord.].- Es probable que el alnoxacar de nuestro documento sea la not ycherca, djouz es-cherc, nux xarch o nux de xarch, nux sarca estudiada por Dorveaux. Para este autor las expresiones citadas corresponden a una especia, pues siempre aparecen junto a otras que lo son, como el gengibre, la pimienta, el girofle, la moscada, la canela, etc. Finalmente, la identifica con la malagueta: "Not ycherca, c'est donc une noix fournie par la plante qui produit la graine de paradis, autrement dit le fruit de l'Amomum Melegueta Roscoe" (DORVEAUX 1914 p. 243). La malagueta es el fruto pequeño, aovado, de color de canela, y de olor y sabor aromáticos, que suele usarse como especia y es producto de un árbol tropical de las mirtáceas.

Alquitira. Alquintira [doc.]. Alquitira [Ord.].Goma de tragacanto, que es un arbusto de la familia de las papilionáceas, que crece en Persia y Asia Menor y de cuyo tronco y ramas fluye naturalmente una goma blanquecina muy usada en farmacia (D.R.A.E.). Es un líquido viscoso que procede de una hendidura hecha en la corteza de diversos árboles de la familia de los astrágalos, y que se endurece en contacto con el aire. Pegolotti indica dos lugares de donde se obtenía este producto en la Edad Media: Grecia y Asia Menor. Era de mayor calidad la procedente de este último. En la Edad Media se elaboraba con ella una bebida (diadragum, diadragagantum o dyadragantum) que se consideraba un remedio refrescante. Por otra parte la industria medieval empleaba la goma de tragacanto en la preparación del azul y del dorado. Es posible que se usara también para fijar la pintura (HEYD 1967: Il, p. 623). "Llaman en algunas partes de España a cierta droga, goma que, a mas de ser algo medicinal suele seruir de engrudo para pegar papeles y cosas delicadas" [P. Guadix].

Alumbre. Alunbre [doc.]. Alumbre [Ord.].Sulfato doble de alúmina y potasa: sal blanca y astringente que se halla en varias rocas y tierras, de las cuales se extrae por disolución y cristalización (D.R.A.E.). Materia prima de extraordinaria importancia en el comercio medieval por ser imprescindible su uso como mordiente en la industria textil (fijación de colores en las telas), además de emplearse en el curtido de cueros y pieles, en la elaboración de vidrios y pergaminos, en la iluminación de libros y códices, en los dorados y pinturas, en embalsamamientos, en farmacopea y como medicina para perros y aves de caza. Los mercaderes genoveses, florentinos, venecianos y catalanes monopolizaron durante mucho tiempo este producto [Voc. Comerc. Med.]. Aunque existían yacimientos en Occidente conocidos desde la época 
medieval su producción era insuficiente y era preciso traerlo de Oriente. La región del alumbre por excelencia era Asia Menor. El alumbre de mayor calidad era el conocido como allume di Rocca o allumen rocae (HEYD 1967: II, p. 565). El azúcar rosado podría ser una clase de alumbre: "En faisant fondre à chaud de l'alun avec de l'eau de roses et du blanc d'oeuf et en faisant réduire, on obtenait une sorte de sucre, l'alumen zuccarinum" [HEYD 1967: II, p. 569). Además, este producto en nuestro documento no se menciona entre los azúcares sino próximo al alumbre.

Amapola. Amapola [doc.]. - Planta de las papaveráceas con flores rojas por lo común y semilla negruzca. Es sudorífera y algo calmante (D.R.A.E.).

Ambar. Cuentas de anbar [doc.]. Quentas de ambar [Ord.].- Resina fósil de color amarillo más o menos oscuro, opaca o semitransparente, muy ligera, dura y quebradiza, que arde fácilmente, con buen olor, y se emplea en cuentas de collares, entre otras cosas (D.R.A.E.). En la Edad Media se desconocía su origen e, incluso, había muchas leyendas al respecto. El ambar no se encontraba exclusivamente en Oriente. En efecto, el cachalote, de donde provenía, no vivía exclusivamente en el Oceáno Indico, si no también en el Atlántico, aunque aquí era menos frecuente. Consecuentemente también se recogía en las costas de Portugal y de España, si bien se consideraba de calidad inferior al oriental. Se usaba en medicina y, sobre todo, como perfume, quizás el más apreciado en la Edad Media, fabricándose con él todo tipo de objetos (HEYD 1967: II, p.57I).

Anime. Anime [doc.]- Resina o goma de diversas especies botánicas de Oriente y de América, usada generalmente en medicina y droguería (D.R.A.E.). "Lagryma, goma o resina de un arbol que se cria en las Indias orientales y occidentales, mui parecida y semejante al incienso y à la myrrha. Su perfúme oloróso y suave fortaléce el celebro y la cabeza. Llámase en Castilla Aníme copál, porque en Mexico, de donde se trahe, se llama copali" (D.A.).

Añil. Añir [doc.]. Miera [Ord.]. Es otro error de transcripción del escribano de las Ordenanzas de la ciudad de Granada. - Pasta de color azul oscuro, con visos cobrizos, procedente, por maceración de agua, de una planta de la familia de las papironáceas (D.R.A.E.). "Llaman en España a un çierto color azul"' [P. Guadix].

Arroz. Arroz [doc.].- Planta anual que se cría en terrenos muy húmedos, cuyo fruto es un grano oval muy rico en almidón. Fruto de esta planta (D.R.A.E.).
Atutía.- Atutia [doc.]. I.Oxido de cinc, generalmente impurificado con otras sales metálicas.2. Ungüento medicinal hecho con atutía. 3. azogue. (D.R.A.E.). "Atuthia... Paréce haver várias espécies de ella. La verdadéra se produce del hollín que se eleva del cobre quando se funde y purifica... Es granosa por defuera, y su colór ceniciento obscúro. La falsa tuthía es la piedra cadmiána ò calamína, que es propiamente el Espódio, y este es un nombre que los Arabes han dado à las raíces de las cañas quemadas, y algunos modernos al marfil quemado. Esta es negra, y ordinariamente mas pesada que la verdadera tuthía... Hácense de ella várias medicinas, y la que tiene mas nombre en las Botícas es la atuthía preparáda. Paréce haver otra espécie de atuthía de la que hace mención el Moro Rasis" (D.A.). En efecto, al-Rāzī , a mediados del s. X, nombra la existencia de una mina de atutía en la costa de Granada, cerca de Salobreña (CATALAN \& DE ANDRÉS 1974: P.24).

Avenate. Avenate [doc.].- Abenat [Ord.]. Bebida fresca y pectoral, hecha de avena mondada, cocida en agua y molida a manera de almendrada (D.R.A.E.). Avena. Especie de grano... Se divide en silvestre y cultivada: la primera es negra y vellosa, la caña gruesa y el grano áspero y moreno; la cultivada se parece más a la cebada y su grano es blanco y liso [D.A.].

Azafrán. Açafran [doc.]. Azafran [ord.]. (Del ár. az-za'farān). Planta de la familia de las iridáceas, cuyas flores tienen un estigma de color anaranjado que se usa como condimento (D.R.A.E:). "Quitada una flor, por la misma parte sale otra: y assi las quitan los dueños del plantío todos los dias, y algunos dos veces, y al dia siguiente vuelve à salir otras hojas, a las quales llaman Manto de azafran" (D.A.). Se da el nombre de azafrán a los estigmas secos de la flor del Crocus sativus. En la Edad Media esta planta estaba expandida por todas las partes de Asia y de Europa. Originaria del Levante fue aclimatada en España desde el siglo $X$, probablemente por los árabes (Heyd 1967: II, p. 668). "Vient ensuite, à l'Est [de Granada], Bas [Baza], où parmi de nombreuses cultures, celle du safran et spécialement pratiquée. La récolte qu'on y fait suffit à toute l'étendue du territoire musulman de l'Andalousie, bien que la consommation soit considerable" (AL-CUMARĪ 1927: p. 245).

Azarcón.- Azarco [doc.]. Azarcon [Ord.]. (Del ár. az-zarqūn). Carbonato de plomo. Minio (D.R.A.E.). "Llaman en algunas partes de España a una droga algo medicinal de color azul" [P. Guadix].

Azofar.Açefar [doc.].Açofar [doc.]. Acifar [Ord.].latón (D.R.A.E.). "Viene del Arábigo Zufar, que significa cosa amarilla, ò colór que luce como el oro"(D.A.). 
Azogue. Açogue [doc.].- Mercurio (D.R.A.E.).

Azúcar. Açucar gafeti, açucar panela, açucar morisco, açucar candi, açucar rosado [doc.].- Cuerpo sólido, cristalizable, perteneciente al grupo químico de los hidratos de carbono, de color blanco, soluble en agua y alcohol, y de sabor muy dulce. Se extrae de la caña dulce, de la remolacha y de otros vegetales. Según su estado de pureza o refinación se distinguen varias clases (D.R.A.E.). Probablemente descubierta por los árabes conquistadores en el antiguo Imperio Sasánida, concretamente en los valles del Tigris y el Eúfrates. De ahí fue transportada hacia Levante, Egipto, a través de Africa del $N$ hasta España y Sicilia. A principios del siglo X, el geógrafo al-Rāzī menciona que ésta ya crecía alrededor de Salobreña, Almuñécar y Elvira (WATSON 199|: p. 8). Nuestro documento cita las siguientes procedentes de la caña de azúcar: gafetí, morisca, candí, panela y rosado. Este último podría ser alumbre en lugar de azúcar [vid. alumbre], aunque también existe un azúcar rosado, que es "el elaborado con extracto de rosas" (D.R.A.E.). El cande o candí es el obtenido por evaporación lenta, en cristales grandes, cuyo color varía del blanco transparente y amarillo al pardo oscuro, por agregación de melaza o sustancias colorantes (D.R.A.E.). El panela es azúcar mascabado en panes prismáticos (D.R.A.E.). El azúcar morisco vendría, tal vez, del Marruecos atlántico (LOPEZ DE COCA 1989: II, p. 17) "[En Salobreña] on y cultive la canne à sucre" (AL- CUMARI 1927: pp. 239-240). "[En Almuñécar] on y trouve la canne à sucre et la banane, qui ne poussent point ailleurs sur le territoire musulman de ce pays, sauf en quantité négligeable. On en exporte du sucre" (AL- CUMARĪ 1927, p. 240). "Llaman en España a una congelaçion blanca y dulçe que se haze del çumo o suco de una suerte de cañas maçiças y dulçes a que llaman (en España) cañas dulçes" [P. Guadix].

Azúcar rosado. Azucar rosado [doc.]- Vid. azúcar y alumbre.

Azufre.- Piedra çufre [doc.]. Açufre [Ord.].Metaloide de color amarillo, quebradizo, insípido, craso al tacto, que se funde a temperatura poco elevada y arde con llama azul, desprendiendo anhídrido sulfuroso (D.R.A.E.). Comunmente se llama assi el xugo mineral o la crassitúd de la tierra, preñada de la calidad acida del vitriolo: y por esto se llama piedra azúfre y tierra azúfre (D.A.).

Bacín.- Baçines [doc.]. Bacines [Ord.] Recipiente de barro vidriado, alto y cilíndrico, que servía para recibir los excrementos mayores del cuerpo humano (D.R.A.E.).

Ballena.- Ballena [doc.]. I. Cetáceo, el mayor de todos los animales conocidos. 2. Aceite, barba, esperma de ballena. 3. Cada una de las láminas córneas y elásticas que tiene la ballena en la mandíbula superior y que, cortadas en tiras más o menos anchas, sirve para diferentes usos. 4. Cada una de estas tiras (D.R.A.E.). En las Ordenanzas de Granada se dice erróneamente el auellana [Ord.].

Bayón. Bayon [doc.]. Bayo [Ord.].- (bodón, espadaña, del lat. buda). Saco de estera hecha con las hojas del burí. Espadaña, planta tifácea (D.R.A.E.).

Befre.- ant. Bíbaro, castor, mamífero roedor de pelo castaño, patas cortas y cola aplastada (D.R.A.E.). En el documento se menciona el cojon de befren [doc.], del que seguramente se sacaba alguna sustancia olorosa para fabricar perfume, como pasaba con el gato de algalia. "Los testículos del castór, que son mui medicinales contra varias enfermedades" (D.A). En las Ordenanzas de la ciudad de Granada aparece como un solo nombre cojodebefre [Ord.].

Bellota. Bellota [doc.]- Fruto de la encina, del roble y otros árboles del mismo género (D.R.A.E.). Dada su riqueza en fécula se usó, en épocas de escasez, para fabricar "panes de hambre" (GARCIA SANCHEZ 198I-82: p.167.).

Bermellón. Bermellon [doc.]. Vermellon [Ord.].Cinabrio reducido a polvo, que toma color rojo vivo (D.R.A.E.).

Bocín. Boçin [doc.]. Albocin [Ord.].- Pieza redonda de esparto o hierro que se pone por defensa alrededor de los cubos de las ruedas de carros y galeras (D.R.A.E.).

Brasil.- Palo de brasil.- Brasil [doc.]. Madera dura, compacta, que procede de un árbol de la familia de las papilionáceas, que crece en los países tropicales, de color encendido como brasas, capaz de hermoso pulimento, que sirve principalmente para teñir de encarnado, y procede del árbol del mismo nombre (D.R.A.E.). "Espécie de arbol, de mádera mui pesada, y de colór encendido como una brasa, el qual hecho pedacitos, y puesto à cocer en agua, sirve para teñir de colorado las lanas, paños y otras cosas" (D.A.). Colorante rojo que se sacaba de este árbol, muy usado en la industria textil medieval (GUAL CAMARENA 1976: p. 239). Es la madera del Coesalpinia Sappan. Los comerciantes árabes lo vendían con el nombre de Bakam. Su color le hacía compararse con las brasas de carbón, de ahí su nombre, lignum brasile. Es poco probable que haya sido importado antes de la época de las Cruzadas. La India, el distrito del Calcuta y la costa de Malabar, en general, producían Brasil. Pero el lugar más importante de producción, tanto por la cantidad como por la calidad, era Ceilán (HEYD 1967: II, p. 587]. 
Buto [doc.]. Birto [Ord.]. Butomáceo.- Dícese de hierbas angiospermas monocotiledóneas, perennes, palúdicas, con bohordo, hojas radicales, flores solitarias o en umbela, frutos capsulares y semillas sin albumen, como el junco florido. Butomeo (D.R.A.E.).

Cadarzo. Cadarço [doc.]. Cadargo [Ord.]. En la copia de las Ordenanzas el escribano ha confundido la "ç" con una "g".- Seda basta de los capullos enredados, que no se hila a torno (D.R.A.E.). "En Murcia llaman assi la camisa del capullo que arrojan fuera para hilar" (D.A.).

Camarmedes [doc.].- No identificada. Tamarindes [Ord.]. El tamarindo es un árbol de la familia de las papilonácea, originario de Asia, con fruto de sabor agradable que se usa en medicina como laxante (D.R.A.E.). Tamarindo, tamarindi (GUAL 1976: p. 434).

Canela.- Canela [doc.]. Corteza de las ramas, quitada la epidermis, del canelo, de color rojo amarillento, y de olor muy aromático y sabor agradable (D.R.A.E.). "Arbol odorífero, que se cria principalmente en la Isla de Ceilán, a quien tambien llaman Cásia o Cinamomo... Es mui util para muchas enfermedades, y se usa para sazonar manjares y bebídas" (D.A.). "Agua de canela. Bebída, que se hace cociendo la canéla, o echándola en infusión, y despues el agua se incorpóra con almíbar de azúcar, con que queda hecha la bebída" (D.A.). Era una de las especias más apreciadas y abundantes de los tiempos medievales, en sus variedades gruesa, menuda, salvaje, en polvo y en flor; empleada como condimento, en diversas fórmulas culinarias, en terapéutica y tal vez como colorante en la industria textil [Voc. Comerc. Med.]. Ya en la Alta Antigüedad se importaba, según parece, de China. Toda la región de la costa Malabar, isla de Ceilán e, incluso, el interior de la India, era conocida también por la producción de canela. Era muy abundante en Alejandría a donde llegaba por el Oceano Indico, el Mar Rojo y el Nilo. En la Alta Edad Media se usaba en Occidente como condimento en la cocina y para la preparación del vino aromatizado. Pero el canelo no era explotado unicamente por su corteza, también sus flores y sus hojas contenían un aceite etéreo usado en la farmacopea. En concreto, las hojas, llamadas follium eran uno de los ingredientes de la triaca. Las hojas de diversas especies de Cinamomum se emplean todavía actualmente en Asia meridional como estimulantes (HEYD 1967: II, p. 595). Al-Arbūlī dice que "La canela, alqirfa (que significa corteza) es caliente, y seca, conforta el estómago y ayuda a la digestión" (DIAZ GARCIA 1980-8I: II, p. 20).

Canfonca o canfoca [doc.]. Alcanfor [Ord.]. En el documento de $150 \mid$ podría tratarse de un error del escribano. Recuerda la palabra italiana canfora, alcanfor. Alcanfor.- Producto sólido, cristalino, blanco, urente y de olor penetrante característico, que se obtiene del alcanforero (D.R.A.E.). "Alcamphor. Goma que prodúce un arbol de extraordinária grandeza por alto y pompóso, el qual se cría en las tierras orientales. Le trahen à Európa de dos géneros, uno en bruto, como se cogió del arbol, y este es de colór roxo; otro purificado por medio de la sublimación: este se tiene por el mejór, y es blanquissimo. Su olór aunque aromático es poco apacible por demasiado vehemente. El sabór picante y amárgo" (D.A.). En el Corán aparece ya el alcanforero como un arbol del Paraíso, que suministra a los elegidos una bebida aromática y refrescante para calmar la sed. En la Edad Media existían dos tipos de alcanfor, con orígenes, además, diferentes: el Cinnamomum camphora Nees, de Sumatra, y el Dryobalanops aromatica Goertn de la isla de Borneo y de China. Los hindúes y los chinos compraban grandes cantidades de alcanfor para embadurnar a sus muertos o perfumar a sus ídolos. El alcanfor Dryobalanops, de calidad superior, era más caro que el Cinnamomum y, a partir del siglo XVI, dejó de venir a Occidente (HEYD 1967: II, p.590). "Llaman en España a una droga mediçinal que tienen los voticarios" [P. Guadix].

Caña fístola. Caña fistola [doc.].- Fruto de un árbol de la familia de las papilionáceas, en forma de vaina cilíndrica de color pardo, que contiene una pulpa negruzca y dulce que se usa en medicina (D.R.A.E.). Planta leguminosa de hojas purgantes. Los mercaderes occidentales que viajaban a Alejandría tenían la ocasión de ver en los jardines de los contornos de la ciudad unos árboles extraños, de los que pendían unas vainas. Estas encerraban una pulpa dulce y ligeramente purgativa. Pero la casia crecía también en las costas occidentales de la India y en la isla de Java (HEYD 1967 : II, p. 602). Casia fistola medicinal, kiyar xánbar [ALCALA 1971: p. 143).

Cardenillo. Cardenillo [doc.].- Mezcla venenosa de acetatos básicos de cobre; es una materia verdosa o azulada, que se forma en los objetos de cobre o sus aleaciones (D.R.A.E.). "Entre los pintores se llama el color verde hermoso, especialmente el sacado del hollín del cobre con los vapóres del vinagre" (D.A.). En it. verderame: "Quella gomma verde, che fi genera nel rame, per umidezza... E se mancasse il rifagallo [rejalgar], si prenda in suo luogo calcina uiua e tartaro, orpimento, uerderame, poluerizzato infieme" (CRVSCA 1976).

Casca.- Caxca molida o en caxca [doc.]. Casca molida [Ord.]. Corteza de ciertos árboles, que se usa para curtir las pieles y teñir artes y aprejos de pesca (D.R.A.E.). 
Cera. Çera; miel e çera de labor[doc.]. Cera[Ord.].- Sustancia sólida, blanda, amarillenta y fundible que segregan las abejas para formar las celdillas de los panales y que se emplea principalmente para hacer velas; también la fabrican algunos otros insectos(D.R.A.E.)

Clavos de giroflé.- Clavos de girofre [doc.]. Clavos de girofe [Ord.]. Capullo seco de la flor del clavero. Tiene la figura de un clavo pequeño, con una cabecita redonda formada por los pétalos y rodeada de cuatro puntas, que son las divisiones del cáliz, de color pardo oscuro, muy aromático y agradable, y sabor acre y picante (D.R.A.E.). "El mas escogido y selecto viene de la India Oriental" (D.A.). El clavo era empleado corrientemente en la Edad Media como ingrediente en ciertos remedios, condimento en la cocina y para la preparación de bebidas aromáticas. Era utilizado ya en tiempos merovingios y, más tarde, las cruzadas debieron acentuar su uso. Se trataba de una de las especias más caras, dos o tres veces más que la pimienta, porque provenía de un lugar más lejano, las islas Molucas. Se sabe que el girofle era, en realidad, la yema de los frutos de la Eugenia caryophyllata. Se vendían previa una operación de limpieza consistente en separar la cabeza del pedúnculo. Los pedúnculos no se tiraban sino que tenían todavía un cierto valor, puesto que contenían, aunque en un grado menor, el mismo aceite que el clavo mismo. Se les vendía con el nombre de fusti o fistuchi di gherofani, y su valor solía ser un tercio del del clavo. También se ponían en venta las cabezas con el nombre de cappelleti. Como las hojas del clavero destilaban aroma, constituían también artículo de comercio (HEYD 1967: II, p.603).

Cobre.- "Qualquier cobre" [doc.].- Metal de color rojo pardo, brillante, maleable y dúctil (D.R.A.E.). La expresión "qualquier cobre" [doc.] nos hace dudar del sentido de esta palabra.

Comino. Cominos [doc.].- Hierba de la familia de las umbelíferas, flores pequeñas blancas y rojizas y semillas de figura aovada, de olor aromático y sabor acre, que se usan en medicina y como condimento (D.R.A.E.). "Llaman en España a cierta similla que sirue de espeçia a algunos guisados" [P. Guadix].

Congrio.- Congrios [doc.]. Pez teleósteo, del suborden de los fisóstomos, que alcanza I ó 2 ms de largo, con el cuerpo gris oscuro, casi cilíndrico, bordes negros en las aletas dorsal y anal y carne blanca y comestible (D.R.A.E.). "Parece que era conocido por los árabes granadinos, si bien este término, el mismo que ofrece P. Alc., silbāh (pl. salābīḥ), sirve para designar varios peces de forma similar: la anguila, el safío o zafío y el congrio (alArbūili \& | |5), produciéndose una confusión des- tacable. Todo parece indicar que era un pescado muy consumido en la baja Edad Media peninsular, tanto fresco como, principalmente, seco o cecial... Igualmente hay referencias a él en O.M (Ordenanzas de Málaga) I50|, estipulándose un precio de $4 \mathrm{mrs}$. la libra de 16 onzas, o bien $8 \mathrm{mrs}$. la de 32 , y siendo catalogado entre los seis mejores pescados de las costas malagueñas, y también en las de Granada, de 1516 y I524, en donde llega a ser el pez más caro" [MALPICA 1984: p. 109).

Coral.- Aunque el documento sólo menciona "el arrova de todo coral" [doc.], todo corl. [Ord.], debe referirse, al igual que en el caso del ámbar, a las cuentas de coral que se obtenían del celentéreo marino (D.R.A.E.). "Arbolillo, que se cria en el centro del mar, blando y de color verde, cuya frutilla es redonda y blanca; el qual en sacandole del agua y que le dá el áire, se endurece y solida y vuelve de un color roxo, sumamente encendido. Es mui útil para muchas enfermedádes, y dél se hacen muchas cosas curiosas, como son, Rosarios, sortijas, escritorios, etc... tiene virtud contra los truenos è relámpagos, è rayos, è contra piedra, è contra tempestad" (D.A.). Es una formación típica de los mares templados y en el Medievo se sacó de los mares Rojo, Adriático y Mediterráneo, en éste, principalmente de las costas de Cerdeña, Córcega, Sicilia, Noráfrica, Marsella y Cataluña. Sus aplicaciones abarcaban un amplio campo que iba desde la medicina y la superstición, hasta la joyería (GUAL 1976: p. 278). Una parte de la producida en las pesquerías occidentales quedaba aquí, pero la gran mayoría estaba destinada a los mercados orientales. Naves catalanas y florentinas solían llevar el coral a Egipto, de donde pasaba a los mercaderes de Oriente.

Çentual [doc.]. Centual [Ord.].- No identificada.

Dátil.- Datil [doc.] Fruto de la palmera, de figura elipsoidal, cubierta por una substancia amarilla (D.R.A.E.). "En cuanto a la palmera (najl), se esparce sobre el racimo de dátiles polvo de su fecundante y así se amugrona en las palmeras mayores, o de sus ramas penden manojos de sus dátiles bien colgados. Si del lado de la palmera macho soplara viento fuerte, debe de restringirse la fecundación y, según la producción del árbol fecundado, se ha de disminuir o aumentar el fecundante" (LUYUN 1988: p. 220).

Esmalte. Esmaltes [doc.].- I.Barniz vítreo que por medio de fusión se adhiere a la porcelana, loza, metales y otras sustancias elaboradas. 2.Color azul que se hace fundiendo vidrio con óxido de cobalto y moliendo la pasta que resulta. 3. Materia durísima que forma una capa protectora del marfil en la corona de los dientes de los vertebrados (D.R.A.E.). El hecho de que en el documento sólo 
se mencione "el arrova de los esmaltes" [doc.], hace que no podamos precisar su significado.

Espejo.- Espejos [doc.]. Tabla de cristal azogado por la parte posterior para que se reflejen en él los objetos que estén delante (D.R.A.E.).

Espique.- Espique [doc.]. "Espicanardi. Una de las espécies de la planta ò mata llamado Nardo, y es la que viene de Syria. Llámase assi porque parece espiga, aunque verdaderamente es raíz" (D.A.). Espicanardo, planta que se cría en la India, medicinal y aromática, dentro del grupo de las especias medievales (GUAL 1976: p. 430).

Estaño. "Qualquier estaño" [doc.]. - Metal más duro, dúctil y brillante que el plomo y de color semejante al de la plata, pero más oscuro (D.R.A.E.). La expresión "qualquier estaño" [doc.] nos hace dudar del sentido de esta palabra. En nuestro documento se habla también de "foja estañada" [doc.], es decir, hoja o lámina de estaño.

Estoraque.- Estoraque [doc.]. Bálsamo muy oloroso, usado en perfumería y medicina, que procede de las incisiones abiertas en el tronco de un árbol de la familia de las estiracáceas (D.R.A.E.). "El mas estimado es de colór roxo, porque tiene mas crasitúd; à diferencia del que es negro y mohoso, y que con facilidad se desmenuza. El estoraque líquido, es la grassa que sale de la corteza del arbol por via de cocimiento" (D.A.).

Fustes. Fustes [doc.]- Parece ser del italiano fusti, plural de fusto, que es una parte de la especia conocida como clavo. El clavo consta de tres partes, cada una de las cuales puede ser objeto de venta y consumo por separado: la cabeza, el pie (gambe) y unas pequeñas puntas (fustes) (FABREGAS 1995: p. 26). El tallo del clavo (fusto en italiano) se distingue por su color más claro y por su menor precio (CHIARINI 1936: p. 162).

No hay que olvidar que existe una palabra muy parecida en catalán, fustet (fustete en castellano). Arbusto cuya madera y corteza cocidas daban un tinte amarillo, muy empleado en el Medievo. Del ár. fustaq.

Galanga. Garingal [doc.]. - Planta exótica de la familia de las cingiberáceas, cuyo rizoma era usado antiguamente en medicina (D.R.A.E.). "Raíz medicinál, que viene de la China, de que hai dos especies, mayór y menór" (D.A.). Dioscórides dice que "la galanga es amicíssima del estómago, conforta mucho la digestion, y vale contra los dolóres de ijada" [LAGUNA 1968: I, p. I3]. Galanga, rizoma de una planta tropical, usada en la Edad Media como aromática y medicinal [Voc. Comerc. Med.]. Es un nombre que deriva de la palabra árabe khalandjan que, a su vez, procede del chino. La prime- ra vez que se la menciona en Occidente es en un formulario de la época de Carlos el Gordo. A partir de entonces se la encuentra mucho en esta parte de Europa. Hay dos clases de galanga, la pequeña que viene de la China (Alpinia officinarum Hance) y la grande de origen asiático (Alpinia Galanga Willd.), de las cuales la primera parecía ser la de mejor calidad (HEYD 1967: II, p. 617). Garingal [doc.].

Gálbano.- Galuanon [doc.]. Galuano [Ord.]. Gomorresina de color gris amarillento, más o menos sólida y de olor aromático, que se saca de una planta de la familia de las umbelíferas, espontánea de Siria. Se ha usado en medicina y entraba en la composición del perfume quemado por los judíos ante el altar de oro (D.R.A.E.).

Gallón.- La expresión gallon corteza [doc.] que aparece en nuestro documento podría referirse a agallas grandes de algún árbol, como la coscoja o el ciprés. De todas formas las agallas de estos árboles aparecen también como mercancías (vid. agallas). En las Ordenanzas de la ciudad de Granada aparece como gallocresta [Ord.].

Goma. "Qualquier goma" [doc.].- Sustancia viscosa e incristalizable que, naturalmente, o mediante incisiones, fluye de diversos vegetales (cerezo, acacias, tragacanto, etc.) y después de seca es soluble en agua e insoluble en alcohol y éter. Disuelta en agua sirve para pegar o adherir cosas (D.R.A.E.).

Grana. Grana [doc.].- I. Cochinilla. 2 Quermes. 3. Excrecencia o agallita que el quermes forma en la coscoja, y que, exprimida, produce color rojo. 4. Color rojo obtenido de este modo. 5. Paño fino usado para trajes de fiesta (D.R.A.E.). La cochinilla es la hembra redondeada de un insecto hemíptero llamado coccus infectorius que se cría en la coscoja (Quercus coccifera L.) y que machacada da un hermoso colorante rojo [Font. I08]. "Paño fino de color purpúreo, llamado assi por teñirse con el polvo de ciertos gusanillos, que se crian dentro del fruto de la coscója, llamada grana" (D.A.). Según Heyd, existían dos tipos de este tinte, uno que se llama grana y que provienen de España, Portugal o en Languedoc, y otro, que es el consumido en Italia, originario del Levante (isla de Creta o Peloponeso), que se llama normalmente quermes. Hay también otra especie de cochinilla que se cría en Polonia, Rusia y Alemania (HEYD 1967: II, p. 607). Mármol dice en su Historia del rebelión y castigo de los moriscos: "Andaba Aben Humeya vistoso delante de todos en un caballo blanco, con una aljuba de grana vestida" (D.A.). "El mejor quermes es el español, que se encuentra sobre todo en las proximidades de Sevilla, Niebla, Medina Sidonia y Valencia, y se exporta a otros países" (AL-BAKRI 1982: p. 37). La obtención de la grana era una 
práctica habitual para los habitantes del reino de Granada. En una provisión real dirigida a los repartidores de la Sierra de Loja, después de la conquista castellana, se dice que si bien ahora el monte pasa a convertirse en tierra de cultivo no se debe impedir que los vecinos continuen con los aprovechamientos habituales, entre los que se encontraba la recogida de la grana: "Otrosi mandamos que la dichas roças que ansy dieredes, segund e como dicho es, agora ny en algund tienpo no se pueda en ellas vedar ny proyvir la yerva, e pasto, e caça, ni la rroça, ny corta, ny villota, ny la grana... ny otras cosas semejantes, ny nynguno de los aprovechamientos comunes e generales que en ellas oviere" [libro de Rozas de Loja, I506]. Coscoja en que nace la grana, chirich (ALCALA 1971: p. 237).

Grasa.- Grasa [doc.]. I. Manteca, unto o sebo de un animal. 2.Goma del enebro. 3. Grasilla, polvo de sandácara (D.R.A.E.). Grassa [Ord.]. Se llama también la goma del enebro, que en las Boticas se dice Vernix (lat.) (D.A.).

Greda. Greda [doc.].- Arcilla arenosa, por lo común de color blanco azulado, que se usa principalmente para desengrasar los paños y quitar las manchas (D.R.A.E.).

Henenta [doc.]. Geneca [Ord.].- Dice Dioscórides: "La Enanthe, llamada tambien Leucanthon". Según Laguna no es la labrusca o vid salvaje, y algunos la identifican con la filipéndula "llamada ansi, por razon de aquellas muchas cabeçuelas que cuelgan de su rayz, y parecen pender de un hilo" (LAGUNA 1968: I, p. 349). Font Quer menciona la Ulmaria (filipendula ulmaria Maximowicz) y la Filipéndula (Filipendula hexapetala Gilibert). Su principal virtud es diurética (FONT 1978: pp. 3|3-3|4).

Hierro.- Filo de fierro e en maços; fierro [doc.]. Filo de hierro en maços [Ord.].- Metal dúctil, maleable y muy tenaz, de color gris azulado, empleado a veces en combinación con otros elementos (D.R.A.E).

Higos.- Fruto de la higuera. El documento habla de higos de la tierra [doc.], es decir, del propio reino de Granada, lo cual no es extraño dada la riqueza y variedad que había en este tipo de fruto. Al-CUmarī menciona especialmente los de Vélez Málaga y los de Málaga: "Enfin elle est remarquable par ses figues que l'on exporte dans le pays de la Garbiya en Andalousie et ailleurs. On en trouve partout dans le pays, hiver comme été, et il ne manque jamais d'une boutique qui en vende" (AL-CUMARI 1927: p.24I). De la variedad de este fruto dejan testimonio los diferentes nombres que se le aplican. Así, vemos en Pedro de Alcalá los siguientes: higuera fruta de higuera, tîne, tin; higuera breual, cijára, cijár; higo temprano, tîne baquîra, tin bicár; higo de comer menudo, tuáyna, tuaynît; higo passado, tîne muyébeça, tin muyebecîn; higo seco abierto, xaréha, xaráih (ALCALA 197I: p. 274). A finales del siglo XVI en el Padre Guadix menciona dos tipos de higos: albacora, que es el higo temprano, y bujaçote o higo grueso. Lo mismo que ocurría con la uva, los moriscos eran especialistas en hacer el higo paso: "Yo [conde de Tendilla] di liçençia a seis onbres nuevamente convertidos vezinos desa çibdad para que vayan al alcaria de Polopos a hazer la pasa y higos del dicho lugar. No les sea hecho mal ni daño alguno. Fecho $X$ de agosto mill DVIII años" (MENESES 1973: I, p. 38I).

Hoja de lata. Hoja de lata [doc.]. - Lámina de hierro o acero, estañada por las dos caras (D.R.A.E.).

Incienso. Ençençio [doc.]. Ornacirco [Ord.].Nos parece que la interpretación de ornacirco en la copia de las Ordenanzas de la ciudad de Granada es un error. Gomorresina en forma de lágrimas, de color amarillo blancuzco o rojizo, fractura lustrosa, sabor acre y olor aromático al arder. Proviene de árboles de la familia de las burseráceas, originarios de Arabia, de la India y de Africa, y se quema en las ceremonias religiosas (D.R.A.E.). El incienso es un jugo blanco lechoso que se obtiene al practicar unas fisuras en la corteza de ciertos árboles de la especie de los Boswelia. La blancura es lo que indica la buena calidad del mismo. Esta y otra especie crecían en la costa de Somalia de donde lo recibió Europa hasta nuestros días. El mejor incienso se producía en el sur de Arabia de donde llegaba por el Golfo Pérsico a Mesopotamia y Persia, hasta acabar en Bagdad y Tabriz (HEYD 1967: II, p. 6I4).

Jabón.- Xabon priet e blanco [doc.]. Jabon prieto y blanco [Ord.]. Pasta que resulta de la combinación de un álcali con los ácidos del aceite u otro cuerpo graso; es soluble en el agua, y por sus propiedades detersorias sirve comúnmente para lavar (D.R.A.E.). "Pasta, o massa consistente, que se forma de azéite, sebo, y legías de las cenizas de diferentes hierbas, lo que sirve para limpiar, emblanquecer y ablandar la ropa u otras cosas" (D.A.). En concreto, sabemos que se utilizaban las de unas plantas llamadas almarjo o barrilla, de los géneros salicornea y salsola, que viven a orillas del mar o en terrenos salitrosos, de cuyas cenizas, también llamadas barrilla, se obtenía la sosa, que se utilizaba para producir jabón. En Granada los Reyes Católicos prohiben que "ninguno pueda vender la çenisa que se hase para el xabon, salvo en la dicha casa del xabón" (A.G.S., E.M.R., leg. 688).

Jauli [doc.], o janli [doc.]. Juanli [Ord.]- Podría ser del árabe hawlī, que significa cordero añal o cordero. Dozy dice que con este término se designa en Africa un tejido de lana oblonga, sinónimo 
de barracân o de haik. En constantinopla se da este nombre (hawlī, hāwlī, hāwlì)a una tela a modo de toalla(DOZY 1967: I, p. 34I).

Jengibre. Gengibre [doc.].- Rizoma de esta planta, de la familia de las cingiberáceas, procedente de la India. El rizoma es de olor aromático, de sabor acre, picante como el de la pimienta, que se usa en medicina y como especia (D.R.A.E.). Gengibre maqui, zengebîl maqui; gengibre valadi, zengebîl beledî [Alc.266]. Estas dos especies son las que nombra Pedro de Alcalá, aunque había otras. La primera, maquí, venía del mercado de la Meca y pasaba por Alejandría para llegar a Europa; la segunda, baladí, derivado del árabe balad, país, era el nombre que los musulmanes afincados en la India daban al jengibre indígena para distinguirlo del de procedencia extranjera. Se usaba como la pimienta (HEYD 1967: II, p. 619).

Lana. "Toda lana" [doc.]- Pelo de las ovejas y carneros, que se hila y sirve para hacer paño y otros tejidos. 2. Pelo de otros animales parecido a la lana (D.R.A.E.).

Latón. "Todo laton" [doc.].- I. Aleación de cobre y cinc, de color amarillo pálido y suceptible de gran brillo y pulimento (D.R.A.E). Alatón, vale también el fruto del árbol llamado Alatonéro o Alméz (D.A.).

Lino. Lino de Alexandria [doc.].- Materia textil que se fabrica con las fibras que se extraen del tallo del lino, planta herbácea de la familia de las lináceas (D.R.A.E.). El lino era muy importante en el reino de Granada, está documentado al menos desde el siglo Xl en la vega de Granada y en la Alpujarra, y su calidad debía ser muy buena, pues se le compara, precisamente con el de Fayyum [AL-BAKRI 1982: p. 24]. Sin embargo, parece que también se importaba lino de Alejandría, que quizá era mejor que el granadino, para satisfacer las exigencias de las clases elevadas. De allí se exportaba al N de Africa, Chipre, Constantinopla, Italia y España (HEYD 1967: p.632).

El lino se arranca cuando todavía tiene algún jugo, extendiéndolo en el suelo para que se seque. Se hacen después unos manojos que se meten en agua en una especie de pozas o albercas, proceso conocido como cocimiento del lino. En la Alpujarra están documentadas albercas para realizar esta operación al final del siglo XV. El mantenimiento de ellas corría a cargo de los bienes habices. Una vez cocido el lino se le deja secar y se majan sus manojos con una maza de madera de encina o de otra parecida hasta quebrantar las cañas, después de lo cual se separa el lino de ellas. En esta región del reino granadino se pagaba el "derecho del lino" junto al del trigo, panizo y alheña (TRILLO 1994: p. 221).
Loreguilla. [doc.].- No identificado. Existe la palabra loriga, pero sus significados son muy diversos, ignoramos de qué se trataba realmente: I. Armadura para defensa del cuerpo hecha de láminas pequeñas e imbrincadas, por lo común de acero. 2. Armadura de caballo para la guerra. 3. Pieza de hierro circular con que se reforzaban los bujes de las ruedas de los carruajes (D.R.A.E.). En las Ordenanzas de Granada aparece como el oruguilla [Ord.].

Macia.- Macis.- Maçias [doc.]. Macias [Ord.]. Corteza olorosa, de color rojo o rosado, en forma de red, que cubre la nuez moscada (D.R.A.E.). Usada como especia en época medieval.

Manteca. Manteca [doc.].- I. Producto obtenido por el batido, amasado y posterior maduración de la crema extraída de la leche de vaca o de otros animales. 2. Grasa consistente de algunos frutos como el cacao. 3. Sustancia grasa con ingredientes usada como afeite o medicamento, pomada (D.R.A.E.).

Matalahúga. Matalavga [doc.] Matalahuba [Ord.].- Matalahúva, anís (D.R.A.E.). "Llaman en España a una similla dulçe a que (por otro nombre) anis... y no es mucho que los christianos le llamasen mata dulçe porque los guio a ello el nombre en que los arabes la nombran, que es habar hulua, que significa granos dulçes" [P. Guadix].

Mazacote. Maçacote [doc.]. Mazacot [Ord.].Mezcla compuesta de piedras menudas, cemento y arena, hormigón. 2. Cenizas de la planta llamada barrilla. 3. En Argentina y Urugay pasta hecha de los residuos del azúcar que, después de refinada, quedan adheridos al fondo y paredes de la caldera. 4. Guisado u otra vianda o cosa de masa, seca, dura y pegajosa (D.R.A.E.).

Miel. Miel; Miel e çera de labor [doc.].- Sustancia viscosa amarillenta y muy dulce, que producen las abejas transformando en su estómago el néctar de las flores (D.R.A.E.). La miel era el edulcorante usado normalmente antes de la difusión del azúcar, que tiene lugar al principio de la Edad Moderna, aunque antes era conocido como producto de lujo.

Mirabolanos o mirobálanos. Mirabolanos [doc.].- Fruto del mirobálano, que es un árbol de la India, de la familia de las combretáceas, cuyos frutos, parecidos a la ciruela o a la aceituna, según la especie, se usan en medicina y en tintorería (D.R.A.E.). "Cierta especie de fruta semejante a la ciruela, que se cria en las Indias orientales y se divide en cinco especies, que son Myrabolános cetrinos, chebulos, beléricos, émblicos, è Indos... Todas cinco especies son un poco purgantes, y utilisimas 
a la Medicina (D.A.). Estas especies eran: mirolabani emlici, los únicos producidos por una euforbiácea, el Phyllanthus emlica L.; mirobalani bellirici, fruto de la Terminalia bellirica Roxb; mirobalani chebuli, procedente de la Terminalia chebula Retz; mirobalani indi, igual a los precedentes, aunque menos grueso porque se le coge antes de madurar; mirobalani citrini, fruto de una variedad del Terminalia chebula. Los mirobálanos crecen principalmente en la India. Eran usados por sus propiedades digestivas, estomacales y ligeramente purgativas. Los árabes los introdujeron en su farmacopea y de ellos pasaron a bizantinos y occidentales. Hoy día se conoce más su uso en curtiduría y tintorería (HEYD 1967: II, p. 640).

Nuez moscada.- Nuez moscada [doc.]. Nuez moxcada [Ord.]. Fruto de la mirística, de forma ovoide, cubierto por la macis, y con una almendra pardusca por fuera y blanquecina por dentro. Se emplea como condimento y para sacar el aceite que contiene en abundancia (D.R.A.E.). "Llámase Moscáda, por el olor que tiene parecido al del almizcle... Se llama tambien la nuez cogida en verde antes de cuajar la cáscara, y conservada en almibar se cubre despues con alcorza: y se llama assi por parecerse à la Moscada" (D.A.). "Llaman en España a çierta conserva de nuezes, fructa que quando tiernas las ponen en almibar o conserva" [P. Guadix]. La que llegaba a Granada procedía de Oriente: "Por el arrova de la nuez moscada de Xarque [Oriente] honze maravedis" [doc.]

Oropimente. Oro pementel [doc.]. Oropimiente [Ord.]. - Mineral compuesto de arsénico y azufre, de color limón, de textura laminar o fibrosa y brillo craso anacarado. Es venenoso y se emplea en pintura y tintorería (D.R.A.E.).

Pailón.- Paylones [doc.]. Pailones [Ord.].- I.Paila. Vasija grande de metal, redonda y poco profunda. Pailon "Vacía grande o vaso de cobre, azófar o hierro, que sirve para labarse los pies, y otros ministerios" (D.A.). Paylones [doc.].

Pasa.- Pasa [doc.]. Passa [Ord.]. I. Uva seca enjugada naturalmente en la vid, o artificialmente al sol o cociéndola en lejía (D.R.A.E.). Este producto se elaboraba en el reino de Granada, especialmente en la Alpujarra y la Costa. "Le raisin sec de cette région [Almuñécar] jouit d'une grande renommée" (AL-CUMARI 1927: p. 240). "Après Almunecar vient Belliš [Vélez Málaga]... il n'y a point en Andalousie une localité qui produise plus de raisins ni de figues sèches" (AL-CUMARĪ 1927: p. 240]. La elaboración de la uva pasa podía hacerse bien secándola al sol, pasa sol (IBN AL-CAWWĀM 1988: II, p. 666), o bien sumergiéndola en lejía pasa lejía- (LUYUN 1988: p. 243). La tradición en la preparación de uvas e higos pasos se mantuvo en época morisca, especialmente en la costa de Granada y en la Alpujarra. Así, en el mes de septiembre de $|50|$ de unos moriscos no pueden ir a Granada a recoger su recompensa por haber apresado a unos moros de allende al estar recogiendo los panizos y haciendo la pasa: "Desimos que por quanto nosotros ovimos tomado e tomamos tres moros de allende çerca del dicho lugar de Escariantes en el mes de agosto que agora paso, los quales tomo la reyna nuestra señora para sy e non podemos al presente yr a la çibdad de Granada a cobrar los maravedis que su alteza nos manda pagar por los dichos moros a cabsa del faser de la pasa e del coger de los panizos..." (TRILLO 1994: p. 197).

Pastel. Pastel [doc.].- Pasta en forma de bolas o tabletas hechas con las hojas verdes de la hierba pastel, que da un hermoso color azul y sirve también para teñir de negro y otros colores (D.R.A.E.). Es lo mismo que glasto (D.A.). Las hojas de esta planta (isatis tinctorea L.) se molían en molinos, se lavaban y fermentaban en las eras, se cocían y se envasaban en barriles. Sabemos que se cultivaba en el país valenciano (GUAL 1976: p.385).

Pedrelongo. [doc.].- Sin identificar. Sabemos que existe el término pebre longo referido a la pimienta, pero no pedrelongo, aunque no excluimos que pueda ser un error del escribano. Si se tratara, como pensamos, de un tipo de pimienta, sería el fruto de una piperácea, el piper officinarum Cas. de Cand. (chavica officinarum Miq.). Bengala, Java y Sumatra, en donde se encontraba, estaban más alejados de Europa que la región que producía la pimienta negra. Este motivo podría explicar por qué el pebre longo era más escaso que la pimienta en los mercados de Occidente (HEYD 1967: p. 664).

Pez. Pez [doc.]- Sustancia resinosa, sólida, lustrosa, quebradiza y de color pardo amarillento, que se obtiene echando en agua fría el residuo que deja la trementina al acabar de sacarle el aguarás (D.R.A.E.). "La resina ò sudor crasso que arroja copiosamente el pino, despues que han desnudado el tronco de la primera corteza, y la recogen en una hoya que hacen à este efecto al rededór del pie, cocida y requemada hasta que se pone mui negra" (D.A.).

Pimienta. Pimienta [doc.]. - Fruto del pimentero. Es una baya redonda, carnosa, rojiza, de unos 4 mms. de diámetro, que toma, cuando seca, color pardo o negruzo; se arruga algo y contiene una semilla esférica, córnea y blanca. Es aromática, ardiente, de gusto picante, y muy usada como condimento. (D.R.A.E.). Fue una de las especias más apreciadas de la Edad Media. La isla de Ceilán y la costa de Malabar eran los principales suministradores de Europa. Mientras que Egipto era el pri- 
mer lugar de tránsito en el comercio de la pimienta de Oriente a Occidente. Aquí, Venecia acapara la mayor parte de este comercio hasta el momento en que los portugueses controlaron los productos de la India. Su comercialización tuvo una gran importancia, por su elevado precio (era consumo preferente de las clases altas), y su poco peso y volumen, que facilitaban su transporte. Se usaba como condimento, en especial, para carnes y pescados. Las clases conocidas en esta época eran la larga, redonda, blanca y negra. Los catalanes la reexportaron a otros lugares. Su valor era tan grande que, a veces, se pagaban con ella impuestos (GUAL CAMARENA 1976: p. 386).

Plomo. Plomo [doc.]- Metal pesado, dúctil, maleable, blando, fusible, de color gris que tira ligeramente a azul. Se obtiene principalmente de la galena (D.R.A.E.).

Pluma. Pluma [doc.].- Cada una de las piezas de que está cubierto el cuerpo de las aves. Serviría para rellenar almohadas y colchones (GUAL 1976: p.395). En las Ordenanzas de Granada viene pimienta [Ord.] en lugar de pluma.

Pólvora.- Polvora [doc.]. Mezcla, por lo común de salitre, azufre y carbón, que a cierto grado de calor se inflama, desprendiendo bruscamente gran cantidad de gases. Empléase casi siempre en granos, y es el principal agente de la pirotecnia (D.R.A.E.).

Queso. Quesos [doc.].- Producto obtenido por maduración de la cuajada de la leche con características propias para cada uno de los tipos según su origen o método de fabricación (D.R.A.E.).

Rejalgar.- Rejalgar [doc.]. Mineral de color rojo, lustre resino y es una combinación muy venenosa de arsénico y azufre (D.R.A.E). Es el arsénico de color blanco y transparente (D.A.).

Resina. Resina [doc.]. Rezina [doc.].- Sustancia sólida o de consistencia pastosa, insoluble en el agua, soluble en el alochol y en los aceites esenciales, y capaz de arder en contacto con el aire. Obtiénese naturalmente como producto que fluye de varias plantas y también artificialmente (D.R.A.E.).

Rocoche. [doc.].- Sin identificar. Existe un alumbre "de roche", que era el de mejor calidad. En las Ordenanzas de Granada aparece como arcoche [Ord.].

Rubia.- Ruuia [doc.]. Ruina [Ord.].- Se aprecia un error evidente en la copia e interpretación del escribano de las Ordenanzas de la ciudad de Granada al sustituir ruuia, es decir, el tinte conoci- do como rubia, por ruina [Ord.]. Raíz de la rubia, planta de la familia de las rubiáceas, originaria de Oriente, que después de seca y pulverizada se utiliza para preparar una sustancia colorante roja muy usada en tintorería (D.R.A.E.). Era cultivada en Europa desde tiempos antiguos, aunque a veces se la traía de Oriente. Pegolotti menciona la robbia di romania (Grecia), de Alessandria y Cipri. La rubia que llegaba a Europa por Alejandría procedía de Arabia y la que llegaba por Chipre, de Siria (HEYD 1967: II, p. 618).

Ruibarbo.- Rubarbo [doc.]. Ruibarbo [Ord]. Planta herbácea de la familia de las poligonáceas, que vive en Asia central y se usa como purgante. Raíz de esta planta (D.R.A.E). "Viene de la China casi siempre, y es mui medicinál y usada en la Európa, como purgante" (D.A.). Se utilizó en medicina medieval en forma de trozos, pastillas, píldoras y polvo. Es la raíz del Rheum officinale Baillon.

Sal de compas. Sal de conpas [doc.]. Sal de compas [Ord.]- Sal gema. Es la común que se halla en las minas o procede de ellas (D.R.A.E.).

Salitre.- Salitre [doc.]- I. Nitrato potásico. 2. Cualquier substancia salina, especialmente la que aflora en tierras y paredes (D.R.A.E.). Los materiales de que se hace la pólvora son tres: salitre, azufre y carbón (D.A.).

Sándalo.- Sándalos [doc.]. Sandolos [Ord.] I.Planta herbácea, olorosa, de la familia de las labiadas. Es originaria de Persia y se cultiva en los jardines. 2. Arbol de la familia de las santaláceas, semejante al nogal y de madera amarillenta de excelente olor (D.R.A.E.). En el Diccionario de Autoridades también se mencionan las dos especies que tienen este nombre, aunque nos inclinamos por que se trata de la segunda, es decir, del árbol venido de oriente, que sería el que tendría valor comercial. "Arbol que se cria en varios parages de las Indias, y en algunas crece à la altura y gruesso de un nogal...hai tres especies, que se distinguen por el color de su madéra, que es medicinal, roxo, blanco, y pálido, que en las Boticas llaman cetrino" (D.A.). Arbol tropical de madera olorosa y fruto parecido a la cereza, usado en el Medioevo en tintorería, medicina y fórmulas culinarias (GUAL 1976: p. 415). Las tres especies nombradas eran ya conocidas en la Edad Media. De ellas la más buscada y más cara era la cetrina, muy usada en Oriente en la incineración de los muertos. Sin embargo, la más frecuente en Occidente era el sándalo blanco de olor más débil. El sándalo rojo se importaba en Europa Occidental en cantidades mayores que los otros dos y se usaba como colorante, por ejemplo, en las salsas (HEYD 1967: II, p. 585). 
Sebo.- Sebo [doc.].- Grasa sólida y dura que se saca de los animales herbívoros, y que, derretida, sirve para hacer velas, jabones y para otros usos (D.R.A.E.).

Seda.- Seda [doc.]. Hilo formado por varias hebras producidas por el gusano de la seda y a propósito para coser o tejer diferentes telas, todas finísimas, suaves y lustrosas (D.R.A.E).En el documento se nombran varias clases, suponemos que dependiendo de su calidad: una a 20 mrs. el arrova y otra a 8 mrs. La seda citada debe ser del propio reino de Granada, ya que aquí la producción de esta materia se encontraba muy desarrollada. Las fuentes árabes mencionan el cultivo del moral en estas tierras, especialmente en Sierra Nevada y en la Vega de Granada, desde mediados del siglo $X$ en adelante. En esta fecha al-Rāzī habla del moral cultivado en Sierra Nevada. Un siglo después al-Bakrī dice que los pueblos de Sierra Nevada "se encuentra la seda de mayor calidad" (AL-BAKRĪ 1982: p. 24). En el siglo XII Idrīsī dice que en el iqlimm de las Alpujarras se recogía seda (harīr) (IDRĪSĪ 1975: $\vee$ p. 575) También en esa época al-Zuhrī señala que la región de Sierra Nevada (Ŷabal Sulayr) "es la que produce más seda del mundo" (HADJ-SADOK 1968: p.65). Ya en época nazarí (s. XIV) Ibn al-Jațīb alaba especialmente la de Jubiles y Andarax, aunque también menciona la de Berja y Dalías (IBN AL-JATīB 1977: p. 130). A mediados del siglo XVI el cronista Luís del Mármol Carvajal destaca las de Orgiva, Berja, Alboloduy y Almería.

Al margen de cronistas e historiadores, la propia legislación fiscal pone de manifiesto en 1502 las diferencias de calidad de la seda del reino de Granada:

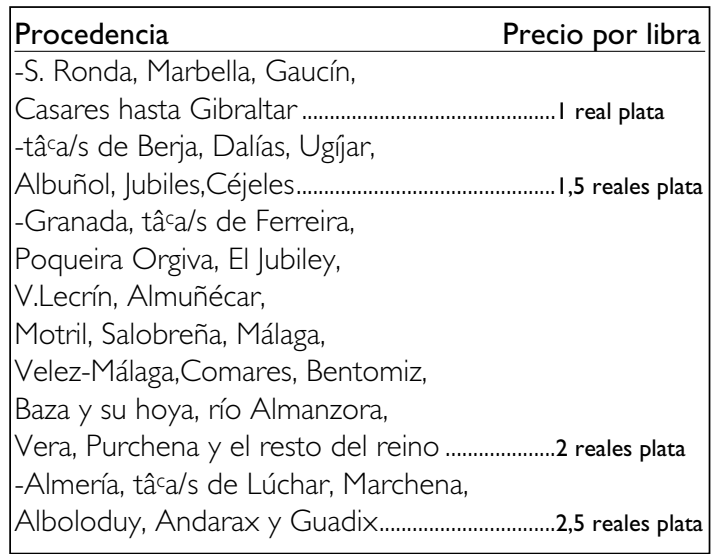

Parece que los derechos de la seda fueron un partido cobrado siempre aparte, según Ladero. Así, no entraría, teóricamente, en el arrendamiento de las rentas de la Alpujarra dado que sus derechos eran recaudados en las alcaicerías de Granada y Almería. Sin embargo, en nuestra relación de impuestos de 1496 hay varios derechos que se cobran sobre "las hojas de los morales", "los capullos de seda" y los "hornos de la seda" (A.G.S., Expte. Ha., leg. 4), y que aparecen con el resto de los tributados por otros conceptos. Por otro lado, la seda constituía un monopolio de la Corona, ya que los señores eran los beneficiarios de las rentas percibidas en sus señoríos a excepción de los derechos de la seda (BEJARANO ROBLES 1951: pp. 188 y 189). En cuanto a si se trata del moral blanco o morera (Morus alba L.) o el moral negro (Morus nigra L.) parece que podrían ser ambos. Ibn al-CAwwām habla del plantío del arbol fersád, que es el moral ó el llamado moral arabigo o de seda (IBN AL-CAWWĀM 1988: I, p. 289). R. Dozy dice que el tūt 'arabī es la mora blanca, sinónimo de farșād (DOZY 1967: p. 154). León el Africano nos informa, al describir Camis Metgara, una población cercana a Fez lo siguiente: "Depuis qu'une partie de la population de Grenade est passée en Maurétanie la ville a commencé a être repeuplée et l'on a planté beaucoup de mûriers blancs parce que les Grenadiens sont de grands marchands de soie" (L'AFRICAIN 1956: I, p. 178). Pero asimismo, al hablar de la ciudad de Cherchel dice que tras la conquista cristiana muchos granadinos vinieron a este lugar y se dedicaron al cultivo de tierras, la construcción de barcos y a la producción de seda "car ils avaient trouvé une quantité infinie de mûriers blancs et noirs" (L'AFRICAIN 1956: II, p. 345). En el siglo XVI Laguna nos informa de que "las hojas del moral que produze las moras blancas, son mas tiernas, y crecen en mayor abundantia, que las del moral negro: por donde son mas utiles para el mantenimiento de los gusanillos que nos fabrican la seda" (LAGUNA 1968: I, pp. |16-117). Sin embargo, la creencia a lo largo de ese siglo sobre todo de que la seda producida con hojas de morera era de inferior calidad a la que se obtenía con los gusanos alimentados con hojas de moral llevó a la redacción de varias ordenanzas en el reino de Granada en las que no sólo se prohibía plantar moreras, sino que se instaba a arrancar las que ya existían (GARZON PAREJA 1972: p. 135). En el reino de Granada: Morera, tūt (LUYUN 1988: p.). Moral arbol conocido, túte, tut; mora fruta deste, túte, tut (ALCALA 197|: p.3|4).

Seda.- Sedas de puercos e de bestias [doc.]. Sedas de puercos y de vestias [Ord.].Cerda de algunos animales, especialmente del jabalí (D.R.A.E.).

Sen.- "Qualquier sen" [doc.]. Arbusto oriental de la familia de las papilonáceas, parecido a la casia y cuyas hojas se usan en infusión como purgantes (D.R.A.E.). La expresión en el documento "qualquier sen" hace pensar que se trate de especies diferentes con cuyas hojas se pueden hacer infusiones purgantes. En las Ordenanzas de la ciudad de Granada aparece "qualquier semilla", creemos que se trata de un error de interpretación del escribano. 
Solimán.- Soliman [doc.]. I. Sublimado corrosivo. 2. Cosmético hecho a base de preparados de mercurio (D.R.A.E). El azogue sublimado (D.A.).

Triaca.- Triaca [doc.]. Atriaca [Ord.]. Confección farmacéutica usada de antiguo y compuesta de muchos ingredientes y principalmente de opio. Se ha empleado para las mordeduras de animales venenosos (D.R.A.E.).

Turbit. Tarvite [doc.]. Turbi [Ord.].- Planta trepadora asiática, de la familia de las convolvuláceas, de largas raíces gruesas que se han empleado en medicina como purgante drástico (D.R.A.E.). Turbit, turbitto (it.), árabe turbit, raíz purgativa de la Ipocoma turpetum proveniente de la India (CHIARINI 1936).

Urchilla. Vrchilla [doc.].- Color violeta que se saca de un liquen que vive en las aguas bañadas por el mar (D.R.A.E.)

Vidrio de olleros. Vidrio de olleros [doc.].Debe referirse a los distintos elementos que se utilizan sobre las vasijas de barro, con objeto de impermeabilizarlas, y que al horno toman un brillo parecido al vidrio.

Violeta. Violetas [doc.].- Planta herbácea de la familia de las violáceas, de color morado o blanco. Es común en los montes de España, se cultiva en los jardines y la infusión de la flor se usa en medicina como pectoral y sudorífico (D.R.A.E.).

Xemis[doc.].- No identificado. En las Ordenanzas de la ciudad de Granada aparece agenuz [Ord.]. En efecto, probablemente podría ser axenuz, es decir, ajenuz, si no fuera porque en nuestro documento aparece como xemiz con i larga. No obstante, podría tratarse de un error del escribano al copiar los aranceles de Sevilla.

Yerva de vastro [doc.].- No hemos identificado la hierba de vastro, aunque en las Ordenanzas de Granada aparece mencionada como yerua del vallestero [Ord.].

Yeso. Yelso [doc.].- Sulfato de calcio hidratado, compacto o terroso, blanco por lo común, tenaz y tan blando que se raya con la uña. (D.R.A.E.). Yelso es yeso [COROMINAS 1976]. En la tā̄a de Berja, en el año 1496, se paga un "derecho del hielso" (TRILLO 1994: p. 309).
Zumaque.- Çumaque [doc.]. Zumaque [Ord.] (Del ár. sumāq). Arbusto de la familia de las anacardiáceas. Tiene mucho tanino y lo emplean los zurradores como curtiente (D.R.A.E.). "Llaman en España a çierta mata o arbusta con cuya hoja hazen el adobo o curtido de cueros y cordovanes" [P. Guadix].

\section{APENDICE DOCUMENTAL}

\section{I50|, marzo-22. Granada.}

Los Reyes Católicos dan el arancel de las mercancías que entraban en la ciudad de Granada, que es el usado en la ciudad de Sevilla.

$$
\text { A'.- A.G.S., R.G.S., I } 50 \text { I-III, sin foliar. }
$$

Don² Fernando e doña Ysabel, por la graçia de Dios, rey e reyna de Castilla, de Leon, de Aragon, etc., a vos, el conçejo, justiçia, regidores, caualleros, ofiçiales e omes buenos desta nonbrada e gran çibdad de Granada, salud e graçia. Bien sabedes que al tienpo que nos fezimos merçed a esta dicha çibdad e para propios della del peso del conçejo della mandamos qaue todas las mercaderias de aver de peso que a la dicha çibdad veniesen e se vendiesen pagasen los derechos propios por el alanzel que nos mandasemos dar e diesemos a la dicha çibdad. E por los del nuestro consejo fue mandado traher algunos aranzeles de los derechos que se llevauan en elos $^{3}$ pesos de las çibdades de Andaluzia, e visto fue acordado que en esa dicha çibdad de Granada se deuian leuar los derechos como se llevauan en la muy noble çibdad de Seuilla, que son los derechos seguientes:



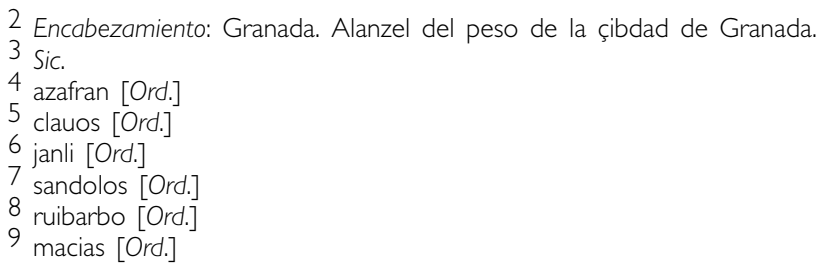


Por el arrova de la nuez moscada ${ }^{10}$ de xarque honze maravedis... XIII Por el arrova de los camarmedes " diez maravedis... $X$.

Por el arrova del atutia diez maravedis... $X$

Por el arrova del alnoxacar ${ }^{12}$ honze maravedis... Xl.

Por el arrova de la canfonca ${ }^{13}$ diez maravedis... $X$.

Por el arrova del $\left(\text { lac }^{14}\right)^{15}$ honze maravedis... XI.

Por el arrova de los mirabolanos ${ }^{16}$ diez maravedis... XI. ${ }^{17}$

Por el arrova de la yerva de vastro ${ }^{18} . . . X$.

Por el arrova del çentual ${ }^{19}$ diez maravedis... $X$.

Por el arrova del garingal diez maravedis... $X$.

Por el arrova del abeytun ${ }^{20}$ diez maravedis... $X$.

Por el arrova del cojon de befren ${ }^{21}$ diez maravedis... $X$.

Por el arrova del açefar ${ }^{22}$ diez maravedis... $X$.

Por el arrova de cuentas de anbar ${ }^{23}$ diez maravedis... $X$.

Por el arrova de todo coral $^{24}$ diez maravedis... $X$.

Por el arrova de los esmaltes diez maravedis... $X$.

Por el arrova del anime diez maravedis... $X$.

Por el arrova de los fustes ocho maravedis... VIII.

Por el arrova del pedrelongo syete maravedis... VII.

Por el arrova de la seda hasta ocho maravedis... VIII.

Por el arrova de la pimienta seys maravedis... VI.

Por el arrova del almaçiga ${ }^{25}$ seys maravedis... VI.

Por el arrova del ençençio ${ }^{26}$ çinco maravedis... V.

Por el arrova del alvayalde ${ }^{27}$ tres maravedis... III.

Por el arrova del hoja de lata çinco maravedis... V.

Por el arrova del açucar ${ }^{28}$ gafeti seys maravedis... VI.

Por el arrova del açucar ${ }^{29}$ panela quatro maravedis...IIII.

Por el arrova del açucar morisco tres maravedis...lll.

Por el arrova del açucar ${ }^{30}$ candi çinco maravedis...V.

Por el arrova del almea çinco maravedis...V.

Por el arrova del alquintira ${ }^{31}$ çinco maravedis...V.

Por el arrova del gallon corteza ${ }^{32}$ dos maravedis...ll.

Por el arrova del alheña tres maravedis...ll.

Por el arrova del alançor ${ }^{33}$ dos maravedis...ll.

Por el arrova de qualquier goma quatro maravedis...III.

Por el arrova de qualquier sen ${ }^{34}$ tres maravedis...III/I

Por el arrova del azarco dos maravedis...l.

Por el arrova de las violetas dos maravedis...ll.

Por el arrova de la aleguz ${ }^{35}$ dos maravedis...ll.
Por el arrova de los alfostigos dos maravedis...ll. Por el arrova del açeyte de laurel ${ }^{36}$ dos maravedis...l. Por el arrova del açeyte de laurel dos maravedis...l. Por el arrova de la $x \mathrm{emis}^{37}$ vn maravedi...l.

Por el arrova del acucar ${ }^{38}$ rosado...l.

Por el arrova de lino de Alexandria...II.

Por el arrova de alunbre ${ }^{39}$ dos...ll.

Por el arrova de las agallas dos maravedis...ll.

Por el arrova de la ruuia ${ }^{40}$ tres blancas... d dinero.

Por el arrova de la piedra çufre ${ }^{4 l}$ vn maravedi e medio... dinero.

Por el arrova de la resina vn maravedi e medio... dinero.

Por el arrova del anir ${ }^{42}$ quatro maravedis...IIII.

Por el arrova del azero vna blanca...dinero.

Por el arrova de qualquier cobre dos maravedis...ll medio. ${ }^{43}$

Por el arrova de qualquier estaño dos maravedis e medio...ll medio.

Por el arrova del pastel VIII dineros corrientes...VIII dineros.

Por el arrova del cardenillo çinco maravedis...V.

Por el arrova del bermellon ${ }^{44}$ quatro maravedis...IIII.

Por el arrova del gengibre seys maravedis...VI.

Por el arrova de la caña fistola çinco maravedis... VI. ${ }^{45}$

Por el arrova del cadarço ${ }^{46}$ çinco maravedis... V.

Por el arrova del açogue ${ }^{47}$ e que lo pague el conprador...IIII.

Por el arrova del oro pementel ${ }^{48}$ çinco maravedis... V.

Por el arrova de la grana çinco maravedis... V.

Del algodon frisado e en palo ${ }^{49}$ çinco maravedis... V.

De la foja estañada tres maravedis...ll.

Del arrova de los baçines e paylones ${ }^{50}$...III.

Otro cualquier açofar çinco maravedis... V.

Del arrova de tarvite ${ }^{51}$ çinco maravedis...V.

Del arrova de soliman çinco maravedis...V.

Del arrova de la triaca ${ }^{52}$ seys maravedis... VI/I

Del arrova del galuanon ${ }^{53}$ tres maravedis...ll.

Del arrova del alfeñique ${ }^{54}$ e confites çinco maravedis... V.

Del arrova de la grasa çinco maravedis...V.

Del arrova de todo laton çinco maravedis... V.

Del arrova de los espejos tres maravedis...III.

Del arrova de la vrchilla vn maravedi....

Del arrova del filo de fierro e en maços dos maravedis...ll.

Del arrova de rejalgar quatro maravedis...IIII.

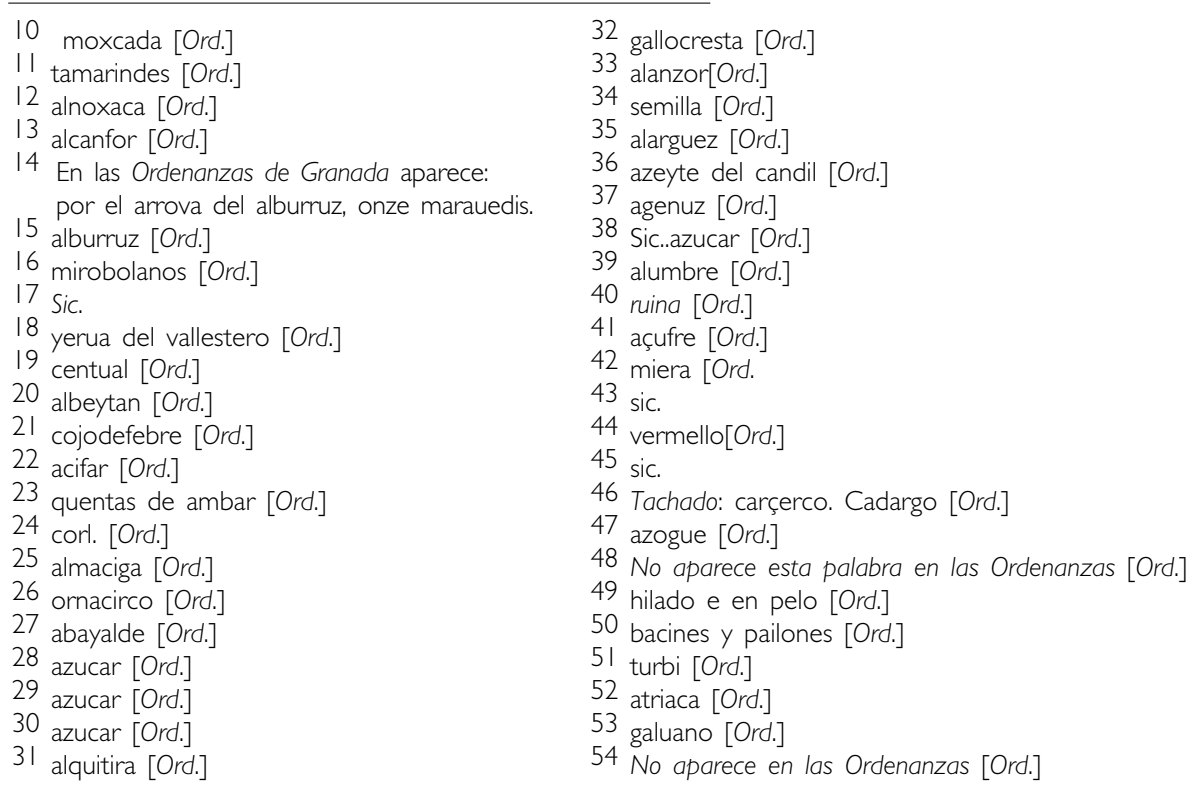


Del arrova del salitre dos maravedis...ll.

Del arrova de la polvora dos maravedis...ll.

Del arrova de sedas de puercos e bestias... dineros. ${ }^{55}$

Del arrova de sal de conpas vn maravedi...

Del arrova del alcaravea ${ }^{56}$ vna blanca...medio.

Del arrova del alhuçema ${ }^{57}$ vna blanca...medio.

Del arrova de matalavga ${ }^{58}$ vn maravedi...

Del arrova del fuste vn maravedi...l.

Del arrova del avenate ${ }^{59}$ vna blanca...medio.

Del arrova del azije vna blanca...medio.

Del arrova del arroz vn maravedi...l.

Del arrova del almendra vn maravedi...l.

Del arrova de los datiles vn maravedi...l.

Del arrova de qualquier pasa ${ }^{60}$ vna blanca... medio.

Del arrova de pluma ${ }^{61}$ vna blanca...medio.

Del arrova de loreguilla ${ }^{62}$ vna blanca...medio.

Del arrova de la amapola vna blanca...medio.

Del arrova de los cominos vna blanca...medio.

Del arrova del alcohol ${ }^{63}$ vna blanca...medio.

Del arrova del plomo vna blanca...medio.

Del arrova del boçin vna blanca...medio.

Del arrova del xabon ${ }^{64}$ prieto e blanco vna blanca...medio.

Del arrova de la ballena ${ }^{65}$ vna blanca...medio.

Del arrova de los congrios vna blanca...medio.

Del arrova del çumaque ${ }^{66}$ vna blanca...medio//.

Del arrova de la caxca ${ }^{67}$ molida o en caxca ${ }^{68}$...medio.

Del arrova de vidrio de olleros ${ }^{69}$ vna blanca ...medio.

Del arrova del rocoche ${ }^{70}$ vna blanca...medio.

Del arrova del maçacote ${ }^{7 l}$ vna blanca...medio.

Del arrova de la manteca vna blanca...medio.

Del arrova de la miel vna blanca...medio.

Del arrova del sebo vna blanca ...medio.

Del arrova de la pez vna blanca...medio.

Del arrova de la rezina ${ }^{72}$ vna blanca...medio.

Del arrova de la almagra vna...medio.

Del arrova de toda la lana vna blanca...medio.

Del arrova del fierro ${ }^{73}$ vna blanca...medio.

Del arrova del bayon ${ }^{74}$ vna blanca...medio.

Del arrova de los quesos vna blanca...medio.

Del arrova de la çera ${ }^{75}$ vn maravedi e medio que los pague el conprador... medio.

Del arrova de los higos de la tierra e sobreman vna blanca...medio.

Del arrova del yelso ${ }^{76}$ vna blanca...medio.
Del arrova del buto ${ }^{77}$ que lo pague el conprador...medio.

Del arrova de la miel e çera de lauor dos comados...ll comados.

Del arrova de la greda vna blanca...medio.

Del arrova del henenta ${ }^{78}$ vna blanca...medio.

Del arrova de la bellota dos cornados...ll comados.

Del arrova de la almoradux ${ }^{79}$ dos comados...ll cornados.

Del arrova del ajonge dos comados...ll cornados.

Porque vos mandamos que veades el dicho arançel que de suso va encorporado e le guardedes e cunplades e fagades guardar e conplir en todo e por todo segund que en el se contiene e contra el tenor e forma del no vayades ni pasades ni consintades yr ni pasar en tienpo alguno ni por alguna manera, so pena de la nuestra merçed e de diez mill maravedis para la nuestra camara, e demas mandamos al ome que vos esta nuestra carta mostrare que vos enplase que parescades ante nos en la nuestra corte doquier que nos seamos del dia que vos enplasare fasta quinze dias primeros siguientes so la dicha pena, so la qual dicha pena mandamos a qualquier escriuano publico que para esto fuere Ilamado que de ende al que vos la mostrare testimonio sygnado con su sygno porque nos sepamos en como se cunple nuestro mandado.

Dada en la çibdad de Granada a veynte e dos dias del mes de março año/l del nasçimiento de nuestro Señor Ihesu Christo de mill e quinientos e vn años.

Yo el rey. Yo la reyna.

Yo Gaspar de Grizio, secretario del rey e de la reyna nuestros señores la fiz escreuir por su mandado.

Joannes episcopus Ouetensis. Felipus dotor. Joanes licenciatus. Martin dotor. Arçediano de Talavera. Liçençiatus Çapata. Françisco Tello. Liçençiatus.

Alonso Peres (rubricado)

\footnotetext{
55 Sic.

56 alcarauela [Ord.].

57 algucema [Ord.].

58 matalahuba [Ord.].

59 abenate [Ord.].

60 passa [Ord.].

61 pimienta [Ord.].

62 oruguilla [Ord.].

63 alcoxol [Ord.].

64 jabon [Ord.].

65 auellana [Ord.].

66 zumaque [Ord.]

67 casca [Ord.].
}

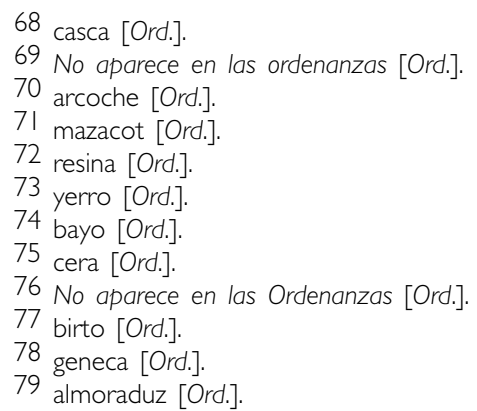




\section{ABREVIATURAS UTILIZADAS}

A.G.S. Archivo General de Simancas

D.A. Dicccionario de Autoridades

D.R.A.E. Diccionario de la Real Academia Española

doc. documento del apéndice documental

E.M.R. Escribanía Mayor de Rentas

Ord. Ordenanzas de Granada

R.G.S. Registro General del Sello

\section{BIBLIOGRAFÍA}

AL-BAKRT̄ (1982): Geografía de España (Kitāb al-masālik wa-I-mamālik). Trad. y estudio Eliseo Vidal Beltran. Zaragoza.

AL-IDRĪSĪ : Opus Geographicarum sive "liber ad eorvm delectationem qvi terras peragrare stvdeant". Consilio et avctoritate E. Cerulli, F. Gabrieli, G. Levi Della Vida, L. Petech, G. Tucci, vna cvn aliis edidervnt. NeapoliRomae, fasc. V.

AL-CUMARī (1927): Masālik el Abșār fī Mamālik el Amșār. Ed. M. Gaudefroy Demombynes. París.

ALCALA, P. (197I): Petri Hispani. De lingua arabica libri duo. Ed. Paul Lagarde. Gottingae, I 883 (reimp. 197I).

CATALAN, D. y DE ANDRÉS, Ma S (1974): Crónica del Moro Rasis. Madrid.

CHIARINI, L. (1936): Libro di mercatantie et usanze de' paesi, Ed. Franco Borlandi, Documenti e Studi per la Storia del Commercio e del Diritto Commerciale Italiano, XIV, Turín, 1936.

COROMINAS, J. (1976): Diccionario crítico etimológico de la lengua castellana. Madrid.

COVARRUBIAS, S (1984): Tesoro de la lengua castellana ( $|6| \mid)$. México.

CRVSCA ( 1976): Vocabolario degli Accademici della Crusca. Venezia, 1612, reimp. Firenze.

Diccionario de Autoridades (1976). Ed. Real Academia Española. Madrid.

Diccionario de la lengua española (1992). Real Academia Española. Madrid,

DORVEAUX, P. (19|4): “Anc. Prov. Notz Ysserca, Not Ycherca", Romania, XLIII, pp. 24I-243.

DOZY, R. (1967): Suppléments aux dictionnaires arabes. Leyde-París, 2 vols.

FABREGAS GARCIA, A. (1995): El comercio mediterráneo del azúcar del reino de Granada en la Baja Edad Media, según la correspondencia existente en el Archivio Datini (Prato, Italia). Granada (Memoria de Licenciatura inédita).
GARCIA SANCHEZ, E. (|98|-82): "La alimentación en la Andalucía islámica. Estudio histórico y bromatológico. I: cereales y leguminosas", Andalucía islámica, II-III, pp. 139-176.

GARCIA SANCHEZ, E. (1990): "El azúcar en la alimentación de los Andalusíes", Actas del Primer Seminario Internacional. La caña de azúcar en tiempos de los grandes descubrimientos (1450-I550). Granada, pp. 209-231.

GARZON PAREJA, M.(1972): La industria sedera en España. El arte de la seda en Granada. Granada.

GONZALEZ JIMENEZ, M. (1981): "Aranceles cordobeses de Portazgo. Aportación al vocabulario del comercio medieval", Estudios de Historia y Arqueología Medievales, I, pp. 45-54.

GUAL CAMARENA, M. (1976): Vocabulario del comercio medieval. Colección de arenceles aduaneros de la Corona de Aragón (siglos XIII y XIV). Barcelona.

HEYD, W. (1967): Histoire du commerce du Levant au Moyen Age. Amsterdan, 1967, 2 vols.

IBN AL-CAWWĀM (1988): Kitab al-Filāha. Traducido al castellano y anotado por Josef Antonio Banqueri en 1802. Ed. J.E. Hernández Bermejo y E. García Sánchez. Madrid.

IBN AL-JAATī̄B (1977): MiČyār al-litiyār fĩ dikr al-Ma ähid wa-I-Diyār. Ed. y trad. Mohammed Kamal Chabana. Instituto Universitario de la Investigación Científica de Marruecos. S.I., 1977.

IBN LUYUN: Tratado de agricultura. Ed. Joaquina Eguaras Ibáñez. Granada.

HADJ-SADOK, M. (1968): "Kitâb al-DjaCarāfiyya. Mappemonde du calife al-Ma'mûm reproduite par Fazārī (III/IX s.) reédité et commentée par Zuhrī (VI/XII). Texte arabe établi avec introduction en français (résumée en arabe)", Bulletin d'Etudes Orientales, XXI, pp. 7-3I2.

L'AFRICAIN, Jean-Leon (1956): Description de l'Afrique. Ed. traducida por A. Epaulard y anotada por A. Epaulard, Th. Monod, H. Lhote y R. Mauny. París, 2 tomos.

LAGUNA, A. (1968): Pedacio Dioscórides Anazarbeo (I555). Madrid (ed. facsímil), Ier tomo. 
LOPEZ DE COCA, J.E. (1978): "Relaciones mercantiles entre Granada y Berbería en época de los Reyes Católicos", Baética, I, pp. 293-3।I.

LOPEZ DE COCA CASTAÑER, J.E. (1982): "Comercio exterior del reino de Granada", Actas del II Coloquio de Historia Medieval Andaluza. Hacienda y Comercio, Sevilla, pp.335-377.

LOPEZ DE COCA, J.E. (1989): "Los genoveses en Málaga durante el reinado de los Reyes Católicos", El reino de Granada en la época de los Reyes Católicos: repoblación, comercio y frontera, Granada, II, pp. 9-55.

MALPICA CUELLO, A. (1984): "El pescado en el reino de Granada a fines de la Edad Media: especies y nivel de consumo", Actes du Colloque Manger et Boire au Moyen Age, t. I, Nice, pp. I03-I 17.

\section{RESUMEN}

Después de la conquista del Reino de Granada los castellanos intentan controlar el comercio uniformándolo con otros de Andalucía. Un ejemplo de ello es el de la propia capital nazarí, en donde se fijan no sólo los itinerarios que debían seguir los productos sino también los aranceles de los mismos. El Siguiente trabajo presenta las tarifas aplicadas a los diferentes artículos que llegan a esta ciudad

PALABRAS CLAVE: Historia Medieval, Granada, Comercio
MENESES GARCIA, E. (1973): Correspondencia del conde de Tendilla en Archivo Documental Español de la Real Academia de la Historia, tomo XXXI. Madrid, vol. I.

TRILLO SAN JOSÉ, C. (1993): "Modificaciones castellanas en la ciudad de Granada a fines de la Edad Media. E control del comercio", Revista del Centro de Estudios Históricos de Granada y su Reino, 7, pp. 27-40.

TRILLO SAN JOSÉ, C. (1994): La Alpujarra antes y después de la conquista castellana. Granada.

WATSON, A (|99|): "Innovaciones agrícolas en el mundo islámico", Actas del II Seminario Internacional de la caña de azúcar en el Mediterráneo. Dirección Este-Oeste. Siglos VII-XVI. Granada, I99I, pp. 7-20.

\section{ABSTRACT}

After the conquest of the Kingdom of Grenada, the Christians try to control the trade, making it similar to other trades in Andalusia. One example is the nasri capital, where not only the routes of the products were fixed, but also their tariffs. This work deals with the tariffs of the different products wich came to this city. 